\title{
A Unilateral Negative Feedback Loop Between miR-200 microRNAs and Sox2/E2F3 Controls Neural Progenitor Cell-Cycle Exit and Differentiation
}

\author{
Changgeng Peng, ${ }^{1} \mathrm{Na} \mathrm{Li},{ }^{2}$ Yen-Kar Ng, ${ }^{1}$ Jingzhong Zhang, ${ }^{1}$ Florian Meier, ${ }^{1}$ Fabian J. Theis, ${ }^{3}$ Matthias Merkenschlager, ${ }^{4}$ \\ Wei Chen, ${ }^{2}$ Wolfgang Wurst, ${ }^{1,5,6}$ and Nilima Prakash ${ }^{1}$ \\ ${ }^{1}$ Institute of Developmental Genetics, Helmholtz Zentrum München, Deutsches Forschungszentrum für Umwelt und Gesundheit, and Technische \\ Universität München-Weihenstephan, D-85764 Neuherberg, Germany, ${ }^{2}$ Berlin Institute for Medical Systems Biology, Max Delbrück Center for Molecular \\ Medicine, D-13092 Berlin-Buch, Germany, ${ }^{3}$ Computational Modeling in Biology, Institute of Bioinformatics and Systems Biology, Helmholtz Zentrum \\ München, Deutsches Forschungszentrum für Umwelt und Gesundheit D-85764 Neuherberg, Germany, ${ }^{4}$ Lymphocyte Development Group, Medical \\ Research Council Clinical Sciences Centre, Imperial College, London W12 0NN, United Kingdom, ${ }^{5}$ DZNE, Deutsches Zentrum für Neurodegenerative \\ Erkrankungen Site Munich, D-80336 Munich, and ' ${ }^{\mathrm{Max}}$ Planck Institute of Psychiatry, D-80804 Munich, Germany
}

MicroRNAs have emerged as key posttranscriptional regulators of gene expression during vertebrate development. We show that the miR-200 family plays a crucial role for the proper generation and survival of ventral neuronal populations in the murine midbrain/ hindbrain region, including midbrain dopaminergic neurons, by directly targeting the pluripotency factor Sox 2 and the cell-cycle regulator E2F3 in neural stem/progenitor cells. The lack of a negative regulation of Sox 2 and E2F3 by miR-200 in conditional Dicer1 mutants $\left(E n 1^{+/ C r e}\right.$; Dicer $1^{\text {flox/flox }}$ mice) and after $m i R-200$ knockdown in vitro leads to a strongly reduced cell-cycle exit and neuronal differentiation of ventral midbrain/hindbrain $(\mathrm{vMH})$ neural progenitors, whereas the opposite effect is seen after $m i R$ 200 overexpression in primary vMH cells. Expression of $m i R-200$ is in turn directly regulated by Sox 2 and E2F3, thereby establishing a unilateral negative feedback loop required for the cell-cycle exit and neuronal differentiation of neural stem/progenitor cells. Our findings suggest that the posttranscriptional regulation of Sox 2 and E2F3 by $m i R-200$ family members might be a general mechanism to control the transition from a pluripotent/multipotent stem/progenitor cell to a postmitotic and more differentiated cell.

\section{Introduction}

The mammalian midbrain/hindbrain region (MHR) harbors several neuronal populations with pivotal functions in normal brain physiology and behavior (Zervas et al., 2005). The development of this region relies on a tight control of gene regulatory networks active in the isthmic organizer ( $\mathrm{IsO}$ ), located at the

Received May 2, 2012; revised July 25, 2012; accepted July 26, 2012.

Author contributions: C.P. and N.P. designed research; C.P., N.L., and Y.-K.N. performed research; J.Z., F.M., and M.M. contributed unpublished reagents/analytic tools; C.P., F.J.T., W.C., W.W., and N.P. analyzed data; C.P. and N.P. wrote the paper.

This work was supported by Bavarian Research Alliance "ForNeuroCell II" GrantF2-F2412.18/10086 (W.W., N.P.), Federal Ministry of Education and Research Joint Project "Neurogenesis from Brain and Skin Cells" Grant FKZ 01 GN1009C (W.W., N.P.), the Initiative and Networking Fund in the framework of the Helmholtz Alliances of Systems Biology and of Mental Health in an Ageing Society Grant HA-215 (W.W.), Federal Ministry of Education and Research National Genome Research Network Plus Project "From Disease Genes to Protein Pathways" Grant FKZ $01 G 50858$ (W.W.), and European Union Seventh Framework Programme Research Network SyBoSS Grant FP7Health-F4-2010-242129 (W.W.). We thank D. Refojo and S. Giusti for the very generous gift of the pCAG-EGFP vector, G. Luxenhofer and A. Huber-Brösamle for the kind gift of pcDNA6.2-EmGFP plasmid, A. Kurz-Drexler for the pLL3.7 vector, and S. Laass for excellent technical assistance.

The authors declare no competing financial interests.

Correspondence should be addressed to either Nilima Prakash or Wolfgang Wurst, Institute of Developmental Genetics, Helmholtz Zentrum München, Deutsches Forschungszentrum für Umwelt und Gesundheit, and Technische Universität München-Weihenstephan, Ingolstädter Landstrasse 1, D-85764 Neuherberg, Germany. E-mail: nilima.prakash@helmholtz-muenchen.de.

DOI:10.1523/JNEUROSCI.2124-12.2012

Copyright $\odot 2012$ the authors $\quad 0270-6474 / 12 / 3213292-17 \$ 15.00 / 0$ midbrain/hindbrain boundary (MHB), and in the dorsal [roof plate (RP)] and ventral [floor plate (FP)] midline of the neural tube, including post-transcriptional or post-translational regulatory mechanisms (Wittmann et al., 2009).

MicroRNAs (miRNAs), a large class of small noncoding RNAs, have emerged as key posttranscriptional regulators of gene expression by targeting specific mRNAs for translational inhibition and degradation (Huntzinger and Izaurralde, 2011). During canonical miRNA biogenesis, miRNAs are transcribed by RNA polymerase II from their own promoter, rendering a larger and in many cases polycistronic primary transcript that is cleaved in the nucleus by a microprocessor complex into an $\sim 70$-nt-long precursor hairpin (pre-miRNA) and subsequently exported into the cytoplasm, in which it is cleaved by Dicer1 (an RNase III enzyme) into the mature $\sim 22 \mathrm{nt}$ miRNA duplex (Krol et al., 2010). One of the miRNA duplex strands is then assembled into the miRNAinduced silencing complex in which it acts as a guide strand for imperfect base pairing with its target mRNAs, encompassing up to several hundred mRNAs for each miRNA (Huntzinger and Izaurralde, 2011). A 7-nt-long "seed" sequence within the 5' terminus of the miRNA is most critical for target recognition in the 3' untranslated region (UTR), 5'UTR, or coding sequence (CDS) of the mRNA (Mallanna and Rizzino, 2010). 
miRNAs are implicated in the regulation of numerous developmental processes, including the maintenance of self-renewing and pluripotent/multipotent embryonic stem cells (ESCs) and/or progenitor cells, and the differentiation of these pluripotent/multipotent cells into fate-committed cells (Pauli et al., 2011). According to their function and their targets in this context, miRNAs have been classified into either "ESC-specific cell-cycleregulating (ESCC)" miRNAs, targeting negative regulators of cell-cycle progression, such as the retinoblastoma proteins, or "tissue-specific" miRNAs targeting (among others) the pluripotency transcription factors (TFs) Sox2, Oct4, Nanog, and c-Myc and the RNA-binding protein Lin28 (Ivey and Srivastava, 2010; Mallanna and Rizzino, 2010; Martinez and Gregory, 2010).

Based on the analysis of conditional mouse mutants for Dicer 1 in the MHR, we uncovered a novel function of $m i R-200$ in the CNS by showing that $m i R-200$ suppresses the expression of Sox2, a TF expressed in neural stem/progenitor cells and crucial for the maintenance of their proliferative capacity and multipotency (Pevny and Nicolis, 2010), and E2F3, a cyclic active TF required for the regulation of cell proliferation, differentiation, and survival (DeGregori, 2002), in neural progenitors. We also show that Sox 2 and E2F3 in turn activate the transcription of miR-200, thereby establishing a unilateral negative feedback loop between the $m i R-200$ family and their targets Sox 2 and E2F3 that regulates the cell-cycle exit and neuronal differentiation of neural stem/ progenitor cells in the murine MHR but most likely also in other regions of the mammalian brain.

\section{Materials and Methods}

Mutant mice. Dicer $1^{\text {flox/flox }}$ female mice (Cobb et al., 2005) were crossed with male $E n 1^{+/ \text {Cre }}$ mice (Kimmel et al., 2000) to obtain $E n 1^{+/ C r e}$; Dicer $1^{+/ \text {flox }}$ mice. Male En $1^{+/ \text {Cre }}$; Dicer $1^{+/ f l o x}$ mice were mated to female Dicer $1^{\text {flox/flox }}$ mice to obtain En1 ${ }^{+/ \text {Cre }}$; Dicer $1^{\text {flox/flox }}$ embryos and pups. $\mathrm{En1}^{+/ \mathrm{Cre}} ;$ Dicer1 $^{+/ f l o x}, \mathrm{EnI}^{+/+} ;$Dicer $^{+/ \text {flox }}$, and En1 $1^{+/+} ;$Dicer $^{\text {flox/flox }}$ mice were used as wild-type controls. Fate-mapping of Dicer1 mutant cells was done by crossing En1 $1^{+/ C r e} ;$ Dicer $^{+/ \text {flox }}$ mice with CAG-CATEGFP transgenic mice (Nakamura et al., 2006). All mouse lines were kept in a mixed genetic background. C57BL/6 mice were purchased from Charles River. Timed pregnant females were used for collection of embryonic stages; noon of the day of vaginal plug detection was designated as embryonic day 0.5 (E0.5). Animal treatment was conducted under federal guidelines as approved by the Helmholtz Centre Munich Institutional Animal Care and Use Committee.

In situ hybridization and histology. Paraffin sections $(8 \mu \mathrm{m})$ were processed for radioactive ( $\left[\alpha-{ }^{35} \mathrm{~S}\right] \mathrm{UTP}$; GE Healthcare) in situ hybridization (ISH) as described previously (Fischer et al., 2007). Riboprobes used were Dicer1 [complementary to exons 21-22 that are deleted in Dicer1 conditional knock-out (cKO) mice], En1, Wnt1, Fgf8, Lmxb1, Otx2, Gbx2, Shh, Pax2, Sef (Il17rd), Spry1, Spry2, Dusp6 (Mkp3), Hes1, Hes3, and Hes5 (Puelles et al., 2004; Fischer et al., 2007, 2011). Details on riboprobes are available on request. Locked nucleic acid (LNA) oligonucleotide-based ISH using unlabeled LNA-modified mmu-miR124 (EQ 56993; Exiqon), mmu-miR-200c (EQ 56944; Exiqon), and scramble-miR control (catalog \#99004-00; Exiqon) detection probes was performed on $8 \mu \mathrm{m}$ paraffin sections as described previously (Silahtaroglu et al., 2007). The LNA-modified detection probes were labeled with $\left[{ }^{35} \mathrm{~S}\right]$ dATP (GE Healthcare) or digoxigenin (DIG)-dUTP using the DIG Oligonucleotide Tailing Kit or DIG Oligonucleotide 3'-End Labeling Kit (Roche) according to the instructions of the manufacturer. Sections were counterstained with cresyl violet ( $0.5 \%$; Sigma) following standard procedures. Images were taken using bright- and dark-field optics on an Axioplan2 microscope or StemiSV6 stereomicroscope, AxioCam MRc camera, and Axiovision 4.6 software (Carl Zeiss) and processed with Adobe Photoshop CS software (Adobe Systems).

Immunostainings. Immunostainings on $8 \mu \mathrm{m}$ paraffin sections and cultured cells were performed as described previously (Peng et al., 2011).
Polyclonal rabbit antisera were directed against cleaved (activated) Caspase-3 (cCaspase3) (1:100; Cell Signaling Technology), Pitx3 (1:300; Invitrogen), serotonin (5-HT) (1:1000; Immunostar), and Tubb3 ( $\beta$ IIItubulin) (1:500; Abcam), polyclonal chicken antisera against green fluorescent protein (GFP) (1:2000; Aves Labs), and polyclonal goat antisera against Sox2 (1:500; Santa Cruz Biotechnology). Monoclonal mouse antibodies were directed against tyrosine hydroxylase (1:600, MAB318; Millipore), Pou4f1 (Brn3a) (1:100; Santa Cruz Biotechnology), Islet1 (Isl1) (1:100; Developmental Studies Hybridoma Bank), Ki67 (1:200; Abcam), and E2F3 (1:100; Millipore). Secondary antibodies were either fluorescently labeled (Alexa Fluor 488/594; Invitrogen) or coupled to biotin/streptavidin-horseradish peroxidase (Jackson ImmunoResearch) and detected using the Vectastain ABC System (Vector Laboratories). Fluorescent images were taken with a confocal laser scanning microscope (FV 1000; Olympus) and processed with Adobe Photoshop CS software.

5-Ethynyl-2'-deoxyuridine labeling. Pregnant dams were injected intraperitoneally with $10 \mu \mathrm{g}$ of 5-ethynyl-2'-deoxyuridine (EdU; Invitrogen) per gram of body weight on E11.5 or E12.5. Embryos were dissected 2 or 24 h later, fixed, dehydrated, and embedded in paraffin. Paraffin sections $(8 \mu \mathrm{m})$ were processed using the Click-iT EdU Alexa Fluor 488 Imaging Kit (Invitrogen) according to the instructions of the manufacturer and double labeled with Ki67 and E2F3 antibodies.

Culture and transfection of primary ventral $\mathrm{MH}$ cells. Primary ventral $\mathrm{MH}(\mathrm{vMH})$ cultures were prepared from E11.5 C57BL/6 mouse embryos as described previously (Peng et al., 2011). Briefly, the basal plate (BP) and FP of the MHR was microdissected and trypsinized in 0.025\% tryp$\sin / 0.1 \%$ DNaseI (Invitrogen) for $5 \mathrm{~min}$ at room temperature. Dissociated cells were plated on poly-D-lysine-coated coverslips at a density of $2 \times 10^{5}$ cells per well in a 24 -well plate and cultured in DMEM/F-12 medium containing $10 \%$ fetal bovine serum (Invitrogen). The medium was switched to DMEM/F-12 containing 2\% B27 supplement (Invitrogen) after $18 \mathrm{~h}$, and cells were transfected with $m i R-200$ sponge vector, miR-200 overexpression (OE) or the corresponding control vectors, or with Pre-miR miRNA precursor mmu-miR-200c (PM11714; Ambion) or Pre-miR miRNA precursor negative control \#2 (NG $\# 2$; AM17111; Ambion) using Lipofectamine LTX and Plus Reagent (Invitrogen). Medium was changed at $1 \mathrm{~d}$ post-transfection $(\mathrm{dpt})$. Cells were fixed in $4 \%$ paraformaldehyde for immunostainings or lysed in RIPA buffer for Western blot analyses at $3 \mathrm{dpt}$. Transfection efficiency of primary cells under these conditions was between 5 and $10 \%$.

Cell counting. Pitx3-expressing $\left(\mathrm{Pitx} 3^{+}\right)$and Pou4f1 ${ }^{+}$cells were counted on three anteroposterior (A/P) position-matched coronal midbrain sections, and $\mathrm{Isl1}^{+}$and $5-\mathrm{HT}^{+}$cells were counted on every fifth serial coronal hemisection through the midbrain or hindbrain of E12.5 control and En1 ${ }^{+/ C r e}$; Dicer $1^{\text {flox/flox }}$; CAG-CAT-EGFP embryos. EdU ${ }^{+}$, $\mathrm{Ki}_{67}{ }^{+}$, Sox $2^{+}$, and E2F3 ${ }^{+}$cells were counted on three A/P positionmatched coronal hemisections through the ventral MHR of E11.5 and E12.5 control and En1 ${ }^{+/ C r e}$; Dicer $1^{\text {flox/flox }}$ (Dicer 1 cKO) embryos. GFP ${ }^{+}$, Sox $2^{+}$, Tubb3 ${ }^{+}$, and $\mathrm{E} 2 \mathrm{~F} 3{ }^{+}$primary vMH cells were counted in 20 random fields per coverslip, and data were collected from at least three independent experiments.

miRNA profiling of $M H$ tissues and differentiating mouse ESC cultures. Tissues comprising the caudal diencephalon, mesencephalon, and rostral rhombomere 1 were microdissected from E10.5 and E12.5 control $\left(E n 1^{+/ C r e} ;\right.$ Dicer $\left.^{+/ \text {flox }}\right)$ and Dicer1 cKO embryos (see Fig. $4 A$ ). Tissues from three embryos were pooled according to genotypes. JM8 (C57BL/6N agouti) mouse ESCs (mESCs) (Pettitt et al., 2009) were cultured and differentiated into glutamatergic neurons following the protocol of Bibel et al. (2007). Samples (cells from a 10-cm-diameter dish or from four wells of a six-well plate) were collected at day 4 (mESCs), day 12 [embryoid bodies (EBs)], and day 20 (neurons) of the differentiation procedure. Successful differentiation of the mESCs into neurons was confirmed in a fraction of the cells by immunostaining for Sox 2 and Tubb3 (data not shown). Total RNA was isolated from MH tissues and cell samples using Trizol Reagent (Invitrogen). The small RNA fraction with a size range of 10-40 nt was separated using flashPAGE Fractionator (Ambion) according to the instructions of the manufacturer, ligated with synthetic RNA adapters, reverse transcribed, and amplified using Illumina sequencing primers. The adapter-ligated libraries were se- 


\begin{tabular}{|c|c|c|c|c|c|}
\hline miRNA & E10.5 Het. & E12.5 Het. & $\begin{array}{l}\text { E12.5 } \\
\text { Dicer1 CKO }\end{array}$ & $\begin{array}{l}\text { E12.5 } \\
\text { Dicer1 CK0/E12.5 Het. }\end{array}$ & $\begin{array}{l}\text { E12.5 Het./ } \\
\text { E10.5 Het. }\end{array}$ \\
\hline mmu-miR-200a & 724 & 290 & 4 & 0.033545 & 0.400552 \\
\hline mmu-miR-429 & 402 & 207 & 4 & 0.046995 & 0.514925 \\
\hline mmu-miR-200b & 864 & 305 & 8 & 0.06379 & 0.353009 \\
\hline mmu-miR-141 & 280 & 136 & 8 & 0.143058 & 0.485714 \\
\hline mтu-miR-200c & 1699 & 474 & 34 & 0.174447 & 0.278988 \\
\hline
\end{tabular}

The last two columns indicate the ratios between genotypes or stages.

quenced for 36 cycles on the Illumina/GAII Sequencer according to the instructions of the manufacturer. For the mapping of small RNA sequencing reads, $3^{\prime}$ adapter sequences were first removed from the sequencing reads using an in-house Perl script (Max Delbrück Center). The reads between 17 and $30 \mathrm{nt}$ were retained and mapped to known mouse pre-miRNA sequences deposited in miRBase (version 16.0) (Kozomara and Griffiths-Jones, 2011) without any mismatches using soap.short software (Li et al., 2008). Downregulated miRNAs in the Dicer1 cKO embryos were determined by comparing the mutant to the heterozygous (control) samples for each embryonic stage analyzed, after excluding the very-low-abundance miRNAs $(<10$ sequencing reads in the control sample) from these lists (Table 1).

Vector constructs. For construction of the miR-200 OE vectors, the $m m u-m i R-200 c / 141$ gene cluster (MGI Symbol 3618750) was amplified from C57BL/6 mouse genomic DNA using the primers in Table 2 and inserted into the pcDNA6.2-EmGFP vector [Addgene plasmid 22741 (Lau et al., 2008)] downstream of the EmGFP sequence to obtain pcDNA6.2-EmGFP-miR-200c-141 OE vector or cloned together with a U6 promoter [from $p L L 3.7$ vector; Addgene plasmid 11795 (Rubinson et al., 2003)] into the $p C A G-E G F P$ vector [generated and kindly provided by Dr. D. Refojo, Max Planck Institute of Psychiatry, Munich/Germany] to obtain $p U 6-m i R-200 c-141-C A G-E G F P$ OE vector (OE-miR-200 vector). The $m m u-m i R-141$ gene was removed from the pcDNA6.2EmGFP-miR-200c-141 vector using $A f e \mathrm{I}$ and $\mathrm{XhoI}$ restriction sites to obtain pcDNA6.2-EmGFP-miR-200c OE vector. Levels of miR-200c and $m i R-141$ expression from the $p c D N A 6.2-E m G F P-m i R-200 c-141$, $p U 6-$ $m i R-200 c-141-C A G-E G F P$, and $p c D N A 6.2-E m G F P-m i R-200 c$ OE vectors were quantified by real time RT-PCR after transfection into HEK293 cells. Expression levels of $m i R-200 c$ and $m i R-141$ were increased by $\sim 50$ - and $\sim 1400$-fold, respectively, after transfection of the pcDNA6.2EmGFP-miR-200c-141 OE vector in HEK-293 cells, and transfection of this vector in primary vMH cultures caused a severe loss of transfected cells compared with the pcDNA6.2-EmGFP control-transfected cells (data not shown). This vector was therefore not used for additional experiments. Transfection of the pcDNA6.2-EmGFP-miR-200c OE vector in HEK-293 cells resulted in an $\sim 1000$-fold increase of $m i R-200 c$ expression but barely detectable miR-141 levels (data not shown). This vector was therefore not used for miR-200 OE experiments in primary vMH cultures.

Construction of the miR-200 sponge vector was done as follows. Because a gene with a 3 'UTR containing a fully complementary sequence to the miRNA can inhibit the function of this miRNA (Ameres et al., 2010; Mukherji et al., 2011), oligonucleotides that are fully complementary to the sequences of the five members of the miR-200 family (Table 2) were synthesized, annealed, ligated, gel purified, and cloned as concatemers into the $p C A G-E G F P$ vector to obtain $p C A G-E G F P-8 x m i R-200$ sponge vector (hereafter named $m i R-200$ sponge vector).

The mouse Sox2 3'UTR (Entrez Gene accession number NM_011443.3) and E2F3 3'UTR (Entrez Gene accession number NM_010093.3) were amplified from C57BL/6 mouse genomic DNA using the primer pairs indicated in Table 2 and cloned into the XbaI site downstream of the luciferase CDS in the $p G L 3$ promoter vector (Promega) to obtain $p$ GL3-Sox2-3' UTR and $p$ GL3-E2F3-3'UTR sensor vectors. Site-directed mutagenesis of conserved $m i R-200 c$ binding sites (BSs) within the mouse Sox2 and E2F3 3' UTRs of these sensor vectors was done using the primers listed in Table 2 and the Quickchange Lightning Multi Site-Directed Mutagenesis Kit (Stratagene) according to the instructions of the manufacturer to obtain pGL3-mut-Sox2-3'UTR or
pGL3-mut-E2F3-3'UTR sensor vectors. The distal and proximal promoter regions of the $m m u-m i R-200 c / 141$ gene cluster (MGI Symbol 3618750) were amplified from C57BL/6 mouse genomic DNA using the primer pairs in Table 2 and cloned into the $p G L 3$ basic vector (Promega) to obtain pGL3-mmu-miR-200c/141 reporter vectors. Sox2 (Entrez Gene accession number NM_011443.3) and E2F3 (Entrez Gene accession number NM_010093.3) CDSs were amplified from E12.5 C57BL/6 mouse brain cDNA using the primer pairs in Table 2 and cloned into pcDNA3.1 (Invitrogen) to obtain pcDNA3.1-Sox2 and pcDNA3.1-E2F3 vectors, respectively.

Transfection efficiency of these vectors in COS-7 and HEK-293 cells was between 80 and $90 \%$.

Luciferase reporter assays. The functionality of $m i R-200 \mathrm{OE}$ and $m i R$ 200 sponge vectors was tested in COS-7 cells (expressing low levels of endogenous miR-200c; data not shown) cotransfected with $300 \mathrm{ng} /$ well pGL3-Sox2-3'UTR sensor vector and $8 \mathrm{ng} /$ well $p R L-S V 40$ (internal transfection control) along with $600 \mathrm{ng} /$ well pcDNA6.2-EmGFP-miR200c-141, pcDNA6.2-EmGFP-miR-200c, pU6-miR-200c-141-CAGEGFP OE vectors or empty control ( $p c D N A 6.2-E m G F P)$ and with or without $600 \mathrm{ng} /$ well miR-200 sponge vector, using Lipofectamine LTX and Plus Reagent (Invitrogen). The miRNA sensor assays were conducted in COS-7 cells cotransfected with $300 \mathrm{ng} /$ well pGL3-Sox2-3'UTR or $p G L 3-E 2 F 3-3^{\prime}$ UTR sensor vectors and 10 or $30 \mathrm{~nm}$ miRNA precursor $m m u-m i R-200 c$ (PM11714; Ambion) or miRNA precursor $\mathrm{NG}^{\# 2}$ (AM17111; Ambion) as negative control. The corresponding rescue assays were done in COS-7 cells cotransfected with $300 \mathrm{ng} /$ well pGL3-mutSox2-3'UTR or pGL3-mut-E2F3-3'UTR sensor, $600 \mathrm{ng} / \mathrm{well}$ pcDNA6.2-EmGFP-miR-200c OE or empty control (pcDNA6.2$E m G F P$ ), and $8 \mathrm{ng} /$ well $p R L-S V 40$ vectors. The $m m u$ - $m i R-200 c / 141$ promoter assays were performed in HEK-293 cells cotransfected with 300 ng/well pGL3-mmu-miR-200c/141 reporter vector and $400 \mathrm{ng} / \mathrm{well}$ pcDNA3.1-Sox2 or pcDNA3.1-E2F3 plasmids. Cells were lysed in passive lysis buffer $30 \mathrm{~h}$ after transfection, and Firefly and Renilla luciferase luminescence were measured in a Centro LB 960 luminometer (Berthold Technologies) using the Dual-Luciferase Reporter Assay system (Promega) according to the instructions of the manufacturers. Firefly luminescence was normalized against Renilla luminescence for each well. Assays were performed in triplicates, and data are derived from three independent experiments.

Quantitative RT-PCR assays. Total RNA was isolated from cultured primary vMH, COS-7, and HEK-293 cells using Trizol Reagent (Invitrogen). One microgram of total RNA was polyadenylated and reverse transcribed using NCode SYBR Green miRNA qRT-PCR Kit (Invitrogen) according to the instructions of the manufacturer. For detection of miRNA expression levels, quantitative RT (qRT)-PCR assays were conducted using the NCode miRNA universal qPCR primer as reverse primer and the specific miRNA forward primers listed in Table 3. The amplification conditions were an initial step at $95^{\circ} \mathrm{C}$ for $10 \mathrm{~min}$, followed by 45 cycles of $20 \mathrm{~s}$ at $95^{\circ} \mathrm{C}$ and $1 \mathrm{~min}$ at $60^{\circ} \mathrm{C}$. All assays were performed in triplicate and included negative controls. The threshold cycle (Ct) value was recorded for each reaction, and the expression level of each miRNA was calculated relative to $U 6 B$, a ubiquitously expressed small nuclear RNA (snRNA). Data are presented as target gene expression $=$ $2^{-\Delta \Delta \mathrm{ct}}$, with $\Delta \mathrm{Ct}=($ target gene $\mathrm{Ct}-U 6 B \mathrm{Ct})$ according to the $2^{-\Delta \Delta \mathrm{ct}}$ method described previously (Livak and Schmittgen, 2001).

Western blot analyses. Cells were processed as described previously (Peng et al., 2007). Antibodies used were rabbit anti-Tubb3 (1:500; Abcam), goat anti-Sox2 (1:500; Santa Cruz Biotechnology), mouse antiE2F3 (1:200; Millipore), and mouse anti-Actb ( $\beta$-actin) (1:2000; Sigma).

Statistics. All values shown are mean \pm SEM. Statistical significance between groups was assessed by paired $t$ tests or independent-samples $t$ tests using the SPSS 10.0 software (SPSS). A value of $p<0.05$ was considered significant.

\section{Results}

Loss of Dicer1 function in the MHR leads to a progressive loss of midbrain/hindbrain tissues and increased cell death

To understand the role of miRNAs in the development of the murine MHR, we deleted the Dicer1 gene in this region by gen- 
Table 2. Primers and oligos used for vector construction and site-directed mutagenesis

\begin{tabular}{|c|c|c|c|}
\hline Gene (application) & Forward primer $\left(5^{\prime} \rightarrow 3^{\prime}\right)$ & Reverse primer $\left(5^{\prime} \rightarrow 3^{\prime}\right)$ & Product length (bp) \\
\hline $\begin{array}{l}\text { mmu-miR-200c + mmu-miR-141 genes } \\
\text { (miRNA overexpression) }\end{array}$ & GCCTCGAGGAAGGCAGCCATTTTGTCTC & GGAGATCTGCCGCTTCTCTTG & 708 \\
\hline $\begin{array}{l}\text { miR200 oligos for construction of } \\
\text { miR-200 sponge vector }\end{array}$ & $\begin{array}{l}\text { 5'-GGATCCACATCGITACCAGACAGTGTTAGCGTCATCATTACC } \\
\text { AGGCAGTATTAGCGTCCATCATTACCCGGCAGTATTAGCGCCAT } \\
\text { CTTTACCAGACAGTGTTAGCGACGGCATTACCAGACAGTATTAA } \\
\text { GATCT- } 3^{\prime}\end{array}$ & $\begin{array}{l}\text { 5'-AGATCTTAATACTGTCTGGTAATGCCGTCGCTAAC } \\
\text { ACTGTCTGGTAAAGATGGCGCTAATACTGCCGG } \\
\text { GTAATGATGGACGCTAATACTGCCTGGTAAT } \\
\text { GATGACGCTAACACTGTCTGGTAACGA } \\
\text { 'GTGGATCC-3' }\end{array}$ & $\begin{array}{l}\text { These oligos were annealed and cloned as } \\
\text { concatemers into } p \text { CAG-EGFP vector. }\end{array}$ \\
\hline
\end{tabular}

mir-200 sponge vector

Sox23'UTR (miRNA sensor assays) Mutant Sox2 3'UTR (miR-200c BS)

E2F3 3'UTR (miRNA sensor assays) Mutant E2F3 3'UTR (miR-200c BS2)

Mutant E2F3 3'UTR (miR-200c BS4)

mmu-miR-200c/141 (Promoter 1) mmu-miR-200c/141 (Promoter 2) Sox2 CDNA (overexpression) E2F3 CDNA (overexpression)
5'-GGATCCACATCGITACCAGACAGTGTTAGCGTCATCATTAC CAGGCAGTATTAGCGTCCATCATTACCCGGCAGTATTAGCGCC ATCTTTACCAGACAGTGTTAGCGACGGCATTACCAGACAGTAT TAAGATCCACATCGTTACCAGACAGTGTTAGCGTCATCATTACC AGGCAGTATTAGGGTCCATCATTACCCGGCAGTATTAGCGCCAT CTTTACCAGACAGTGTTAGCGACGGCATTACCAGACAGTATTAA GATCCACATCGTTACCAGACAGTGTTAGCGTCATCATTACCAGGC AGTATTAGCGTCCATCATTACCCGGCAGTATTAGCGCCATCTTTA CCAGACAGTGTTAGCGACGGCATTACCAGACAGTATTAAGATCCA CATCGTTACCAGACAGTGTTAGCGTCATCATTACCAGGCAGTATTA GCGTCCATCATTACCCGGCAGTATTAGCGCCATCTTTACCAGACAG TGTTAGCGACGGCATTACCAGACAGTATTAAGATCCACATCGTTA CCAGACAGTGTTAGCGTCATCATTACCAGGCAGTATTAGCGTCCA TCATTACCCGGCAGTATTAGGGCCATCTTTACCAGACAGTGTTAG CGACGGCATTACCAGACAGTATTAAGATCCACATCGTTACCAGAC AGTGTTAGCGTCATCATTACCAGGCAGTATTAGCGTCCATCATTA CCCGGCAGTATTAGCGCCATCTTTACCAGACAGTGTTAGCGACGG CATTACCAGACAGTATTAAGATCCACATCGTTACCAGACAGTGTT AGCGTCATCATTACCAGGCAGTATTAGCGTCCATCATTACCCGGC AGTATTAGCGCCATCTTTACCAGACAGTGTTAGCGACGGCATTAC CAGACAGTATTAAGATCCACATCGTTACCAGACAGTGTTAGCGTC ATCATTACCAGGCAGTATTAGCGTCCATCATTACCCGGCAGTATT AGCGCCATCTTTACCAGACAGTGTTAGCGACGGCATTACCAGACA GTATTAAGATCT-3'

TTAACGCAAAAACCGTGATG

CGATGAAAAAAAAGTTTTAATATTTGCAAGCAACTTTTGTAGTGA TAATATCGAGATAAACATGGCAATCAAATGTCCATTGTTTATAA TAAGGGGCTTAACTGGCGTA

GTAGTATCTGGCACACAAAGTAGATGAGTACTAGTCATAATTTGT TACTTTAAGTCCTGAGATGCAGGTTCCC

TGTCGTACATGTAGCTCTGTCTGTAAATAGAATGGTCATAATAA AGCTTTAGCTTTCAGGAAAAACGAAGTAAGAA

CACACACAAATTACAAGGGAAAAG

GGATCCAAAGATGGCCTCTTTC

GGCGAATTCATGTATAACATGATGGAGACGGAGC

AAGAGCAGGAGGGAGAGATG
1038

CAAGACCACGAAAAGGGTCT $\quad 516$

ACTCCCAGTGTTGGGAGAAA 736

CCTGCAGGCACACAGGTGATGGCCC

$144(-1286$ to -1143$)$

СTCTCGCTCTTCCTCCTTCA

TCTCGAGAGTCCAGCCCTCACATGTGGGACA

GGACAACACTGCGATACACG
$268(-686$ to -419$)$

970

1469

Mutated nucleotides are underlined and in italics.

Table 3. Primer and PCR conditions used for $q R T-P C R$ analyses

\begin{tabular}{llll}
\hline Gene (application) & Forward primer $\left(5^{\prime} \rightarrow 3^{\prime}\right)$ & $\operatorname{Tm}\left({ }^{\circ} \mathrm{C}\right)$ & Cycles \\
\hline mmu-miR-200c (qRT-PCR) & TAATACTGCCGGGTAATGATGG & 60 & 45 \\
mmu-miR-141 (qRT-PCR) & TAACACTGTCTGGTAAAGATGG & 60 & 45 \\
U6B RNA (qRT-PCR) & CGCAAGGATGACACGCAAATTCG & 60 & 45 \\
\hline
\end{tabular}

erating $E n 1^{+/ C r e}$; Dicer $1^{\text {flox/flox }}$ (hereafter referred to as Dicer1 cKO) mice. The Dicer1 $c K O$ pups died shortly after birth, probably as a result of feeding problems (data not shown). After En1 ${ }^{+/ C r e}$ mediated recombination of the floxed Dicer1 alleles at approximately E9.0 (Puelles et al., 2004), Dicer1 mRNA was not detected within the En1 ${ }^{+}$MHR of the Dicer1 cKO mice from E9.5 onward (Fig. 1A). Expression of $m i R-124$, one of the most abundant miRNAs in the brain (Lagos-Quintana et al., 2002), was already strongly reduced within the $\mathrm{EnI}^{+}$domain of the Dicer $1 \mathrm{cKO}$ embryos at E11.5 and completely lost at E12.5 (Fig. $1 \mathrm{~B}$ ), indicating that the loss of Dicer1-mediated processing of pre-miRNAs in the mutants at E9.5 abolishes the expression of mature miRNAs 2-3 $\mathrm{d}$ later. In line with this finding, the first morphological changes in the MHR of the Dicer1 cKO mice became visible at E12.5. A progressive thinning of the $\mathrm{MH}$ neuroepithelium was evident from E12.5 onward, and a progressive loss of dorsal and ventral
$\mathrm{MH}$ tissues became visible at E14.5 in the Dicer1 cKO embryos, resulting in the complete absence of dorsal $\mathrm{MH}$ structures, such as the superior/inferior colliculi and the cerebellum, in the postnatal day 0 (P0) Dicer1 cKO pups (Fig. 1C). Fate-mapping of the $\mathrm{EnI}^{+}$and Dicer1 ${ }^{+/-}$or Dicer $1^{-/-}$cells in En1 ${ }^{+/ C r e} ;$ Dicer $1^{+/ \text {flox }}$ and Dicer 1 cKO $\times$ CAG-CAT-EGFP mice showed that En ${ }^{+}$ $\left(\mathrm{GFP}^{+}\right)$cells were almost entirely absent in the dorsal MHR of the mutant mice at P0 (Fig. 1C). Apoptotic cell death (assessed by the expression of cCaspase3) was massively increased in the dorsal MHR of the Dicer 1 cKO embryos from E11.5 onward (Fig. $1 D$ and data not shown). Notably, apoptotic cell death was not as pronounced in the ventral MHR of the Dicer1 cKO embryos (Fig. $1 D$ and data not shown). Altogether, these data indicate that the absence of Dicer1-processed mature miRNAs in the MHR results in a progressive loss of dorsal and ventral $\mathrm{MH}$ tissues, which is in part attributable to the reduced survival of the corresponding cells.

\section{Establishment of the MHB and patterning of the MHR are not} affected in the Dicer1 $\mathrm{cKO}$ embryos

The MHR phenotype of the Dicer1 cKO mice, although temporally delayed, strongly resembled the MHR phenotype of mouse mutants for the IsO genes Wnt1 (McMahon and Bradley, 1990), Fgf8 (Chi et al., 2003), En1/2 (Wurst et al., 1994; Simon et al., 
A

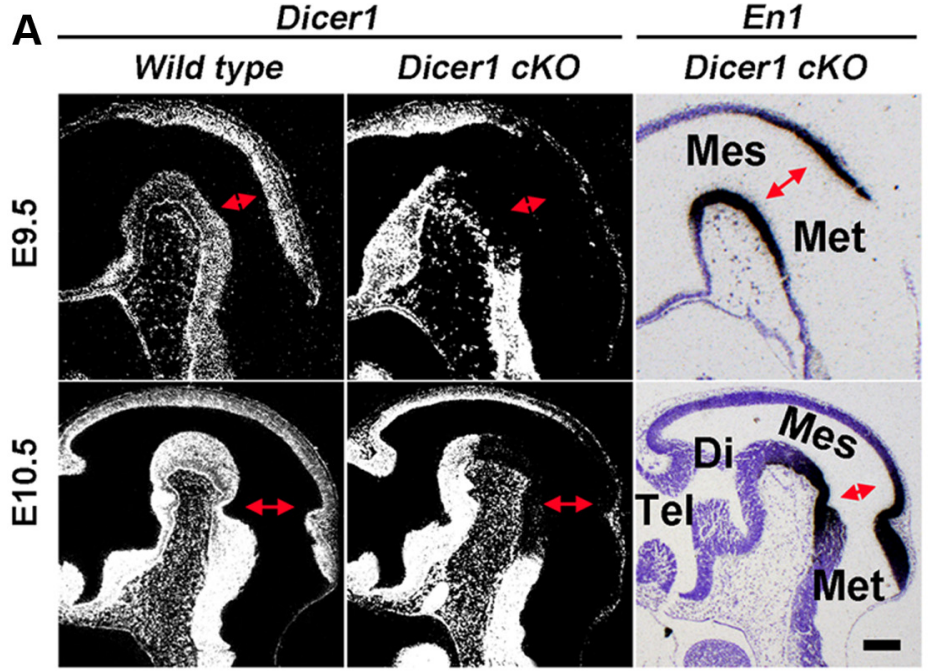

B

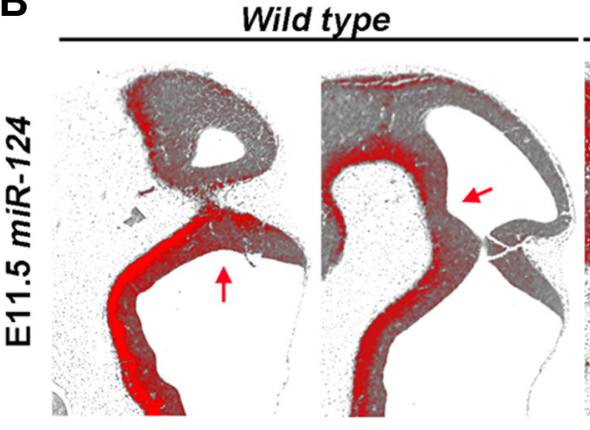

Wild type

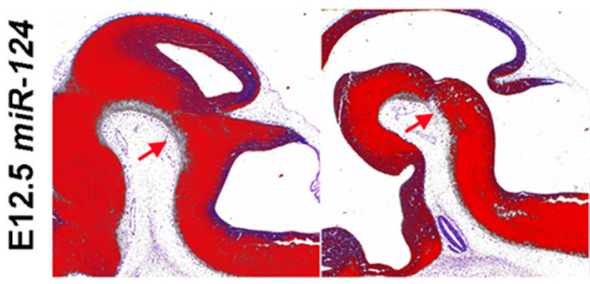

D

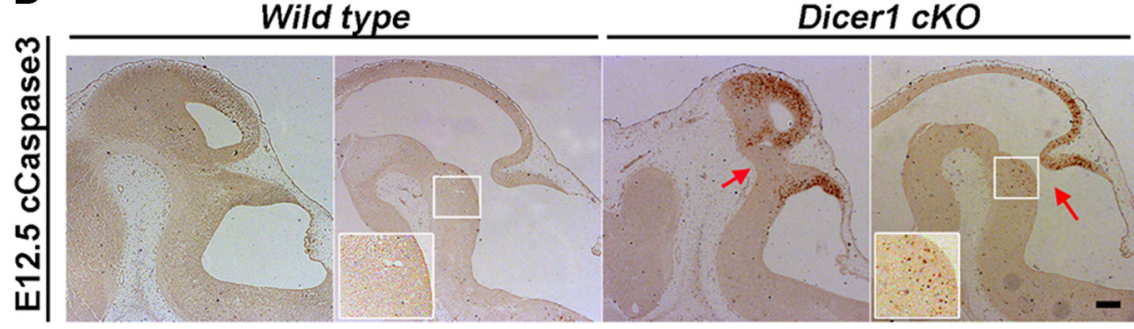

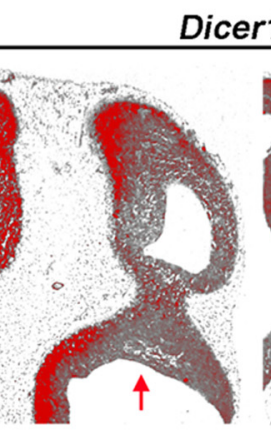

Dicer1 cKO

C

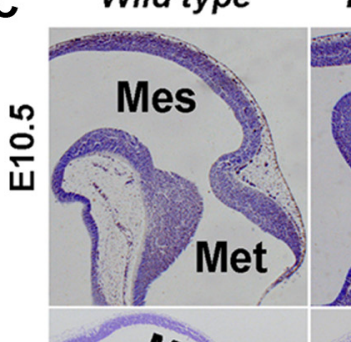

Dicer1 cKO
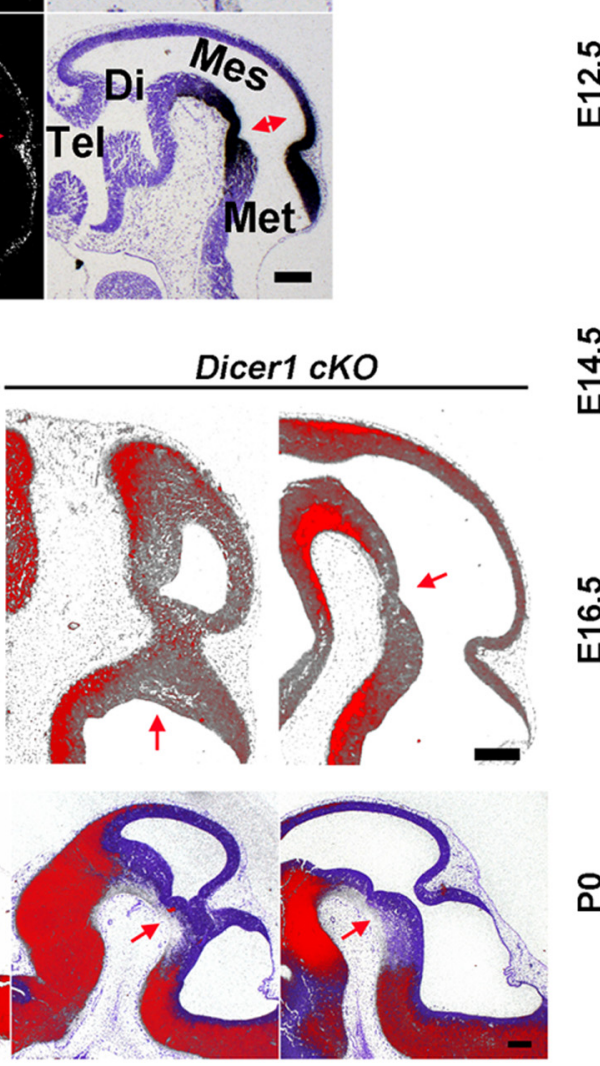

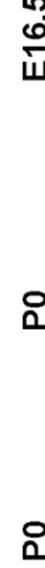
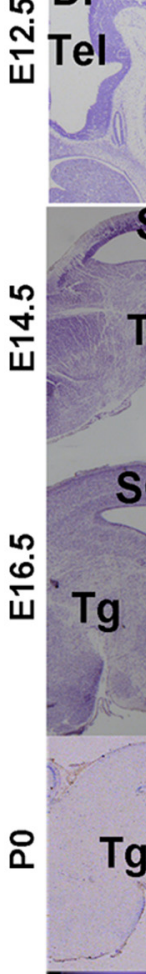

$\stackrel{n}{+}$
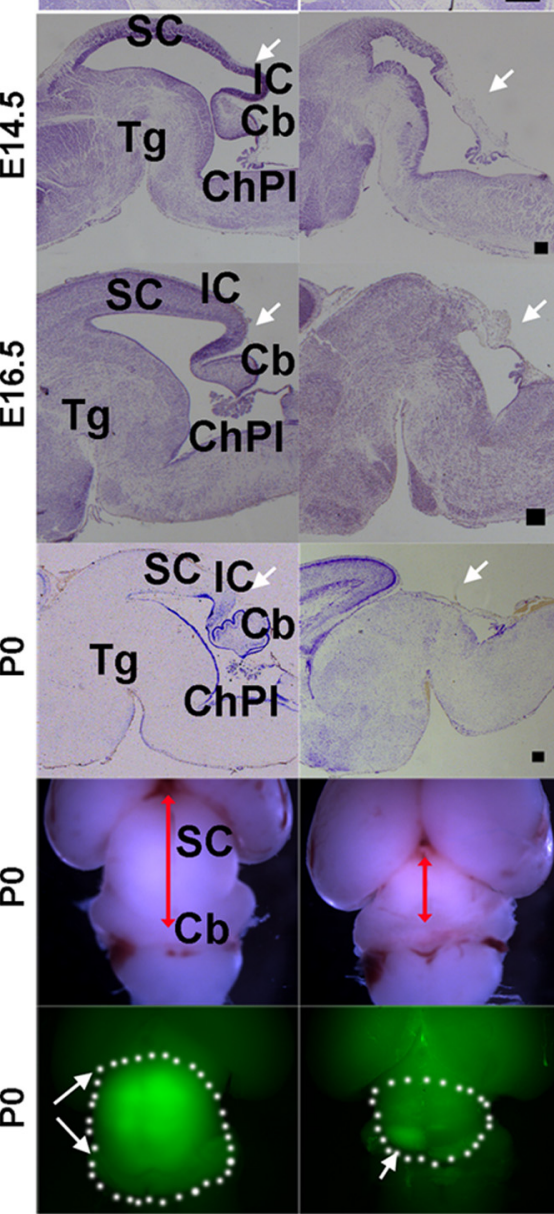

Figure 1. Loss of Dicer 1 function in the MHR leads to a progressive loss of MH tissues and increased cell death. $A$, Dicer1 expression was abolished within the $E n 1^{+}$domain of Dicer $1 \mathrm{cKO}$ mice from E9.5 onward. Red double arrows mark the approximate position of the MHB. Scale bar, $100 \mu \mathrm{m}$. B, Decreased expression at E11.5 and absence at E12.5 of mature miR-124 in the MHR of Dicer 1 CKO embryos (red arrows). Scale bar, $100 \mu \mathrm{m}$. C, A thinner MH neuroepithelium was apparent at E12.5, and a progressive loss of dorsal and ventral MH tissues became visible in the Dicer1 $C K 0$ embryos at E14.5, resulting in the complete absence of the midbrain and rostral hindbrain in P0 mutant pups (white arrows). Bottom panels, Dorsal views of the MHR in En $1^{+/ /(r e}$; Dicer1 ${ }^{+/ f l o x}$; $C A G-C A T-E G F P$

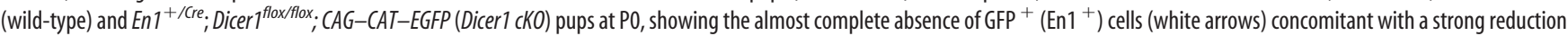
of the dorsal MHR (red double arrows and white circles) in the Dicer $1 \mathrm{CKO}$ mice. Scale bars, $200 \mu \mathrm{m}$. D, Massive increase of apoptotic (cCaspase $3^{+}$) cells in the dorsal MHR, whereas vMH tissues were less affected (red arrows and insets) in the Dicer1 CKO embryos at E12.5. Scale bar, $100 \mu \mathrm{m}$. Cb, Cerebellum; ChPI, choroid plexus; Di, diencephalon; IC, inferior colliculus; Mes, mesencephalon; Met, metencephalon; SC, superior colliculus; Tel, telencephalon; Tg, tegmentum.

2001), Lmx1b (Guo et al., 2007), and Pax2 (Schwarz et al., 1997). We therefore assessed the expression of these IsO and other A/P $(O t \times 2, G b \times 2)$ and dorsoventral (D/V) (Shh) patterning genes in the Dicer1 cKO embryos, but their expression was not altered in the MHR of the mutant embryos at E9.5, E10.5, and E12.5 (Fig. $2 \mathrm{~A}$ and data not shown). Because the protein but not the mRNA expression levels of some of these genes might be affected in the Dicer 1 cKO embryos and because of the lack of working antibodies for some of the crucial IsO factors, such as Wntl and Fgf8, we used an indirect approach to address this issue by detecting known direct target genes and negative modulators of the Fgf8 signaling pathway in the Dicer1 cKO embryos. However, the ex- 

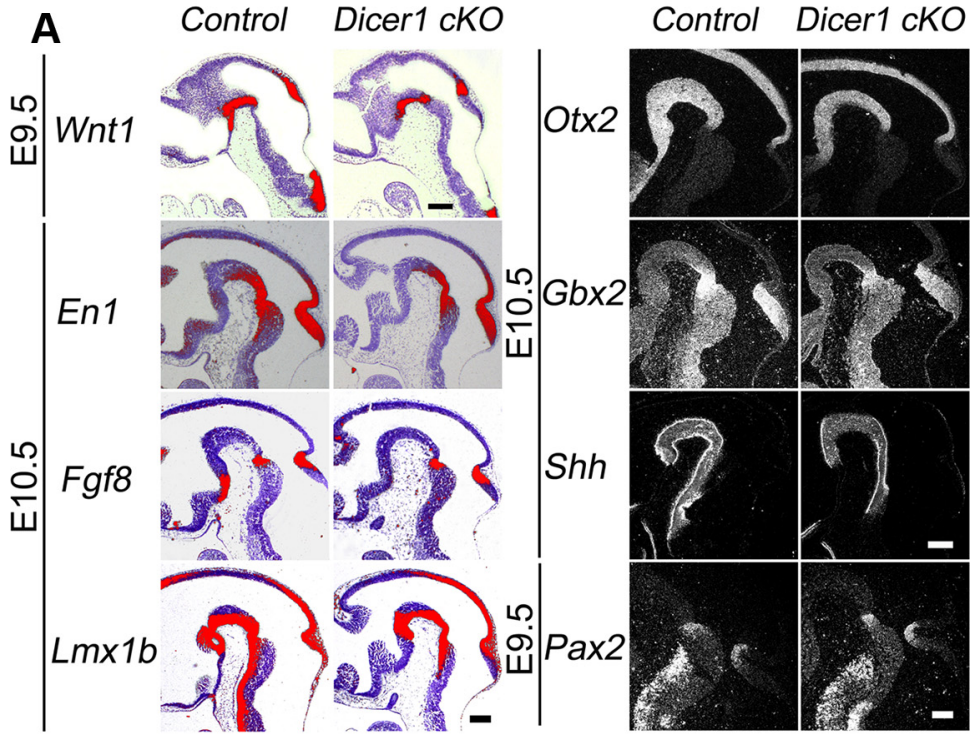

B

E10.5

E12.5

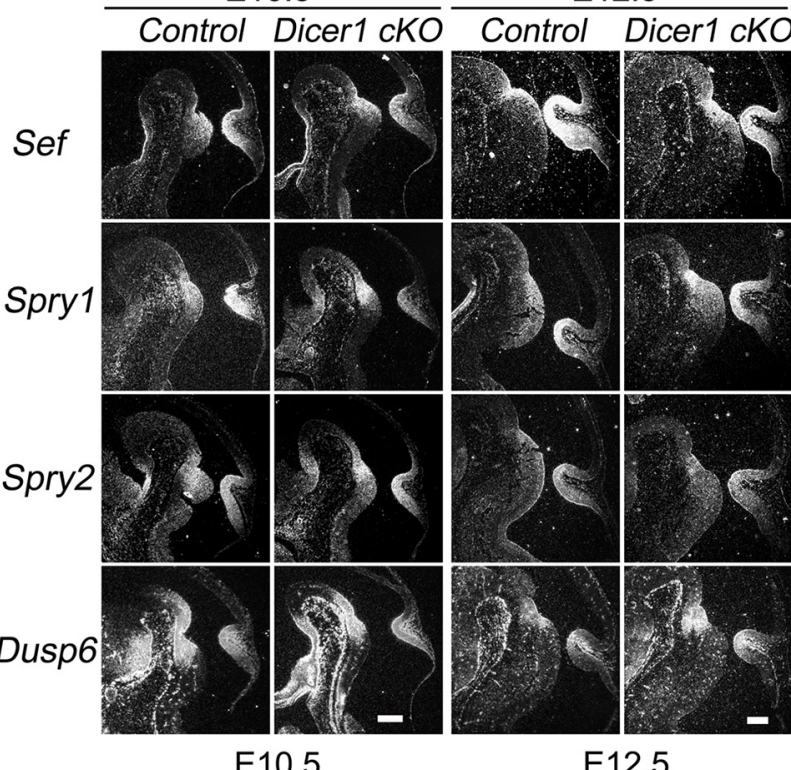

C

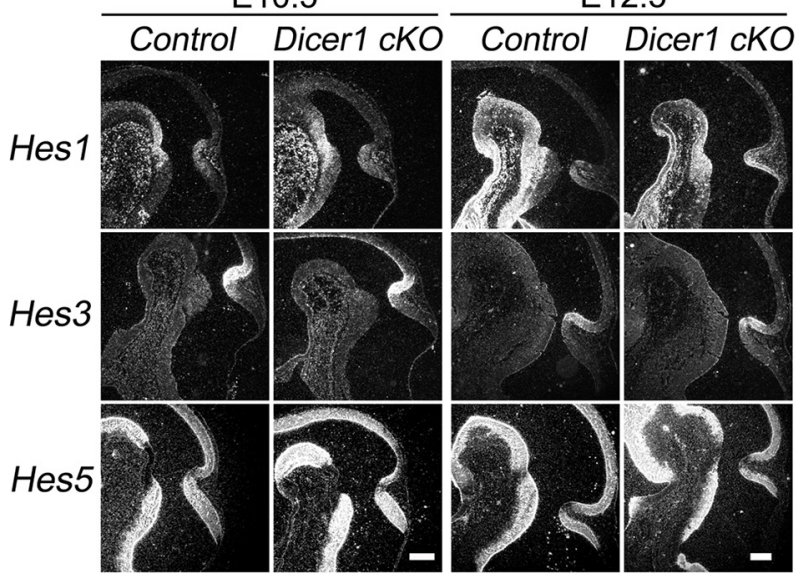

Figure 2. Patterning of the MHR is not affected in Dicer1 CKO embryos. $\boldsymbol{A}$, Expression of the Is0 or FP genes Wnt1, En1, Fgf8, Lmx1b, Otx2, Gbx2, Shh, and Pax2 was not altered in the Dicer1 CKO embryos at E9.5 or E10.5 ( $n=3$ embryos/genotype/stage). $\boldsymbol{B}$, Expression of the direct target genes of the Fgf8 signaling pathway, Sef1, Spry1/2, and Dusp6, was not affected in the Dicer1 cKO embryos at E10.5 or E12.5. C, Expression of the anti-neurogenic bHLH TFs Hes1, Hes3, and Hes5 was not altered in the Dicer 1 CKO embryos at E10.5 or E12.5. Scale bar, $200 \mu \mathrm{m}$. pression of Sef (Il17rd), Spry1, Spry2, and Dusp6 (Mkp3) (Guillemot and Zimmer, 2011) was also not altered in the MHR of the mutant embryos at E10.5 and E12.5 (Fig. $2 B)$. Finally, a loss of $\mathrm{MH}$ tissues might result from a precocious differentiation and failure to maintain the $\mathrm{MHB}$ as a result of the lack of the anti-neurogenic basic helixloop-helix (bHLH) Hes TFs (Hirata et al., 2001), but again the expression of Hes1, Hes3, and Hes5 was not affected in the MHR of the Dicer1 cKO embryos at E10.5 and E12.5 (Fig. 2C). Our data thus indicate that the $\mathrm{A} / \mathrm{P}$ and $\mathrm{D} / \mathrm{V}$ patterning of the $\mathrm{MHR}$ and the maintenance of the MHB are not affected by the loss of Dicer1-processed mature miRNAs in this region of the brain.

vMH neural progenitors do not generate the appropriate number of neuronal offspring and fail to exit the cell cycle in the Dicer 1 cKO embryos Apoptotic cell death was strongly increased in the dorsal MHR, but ventral neural tissues appeared less affected in the Dicer1 cKO mice (Fig. 1). To determine the extent of vMH tissue loss and to establish whether the neuronal populations arising from the ventral MHR [the GFP ${ }^{+}$ $\left(\mathrm{En} 1^{+}\right)$domain in Dicer1 cKO; CAGCAT-EGFP embryos] develop normally in the mutant embryos, we assessed the identity and numbers of midbrain dopaminergic (mDA), red nucleus $(\mathrm{RN})$, and oculomotor (OM) neurons residing in the ventral midbrain and of serotonergic (5HT) neurons residing in the ventral rostral hindbrain. In fact, only $\sim 10 \%$ of the Pitx $3{ }^{+} \mathrm{mDA}, \sim 24 \%$ of the Pou $4 \mathrm{f} 1{ }^{+} \mathrm{RN}$ neurons, and $\sim 67 \%$ of the Isl $1^{+} \mathrm{OM}$ neurons in the ventral midbrain and $\sim 53 \%$ of the $5-\mathrm{HT}^{+}$neurons in the rostral hindbrain persisted in the Dicer 1 cKO embryos at E12.5 (Fig. 3A-U), the time point when the first subtle morphological alterations were detected in the dorsal MHR of the mutant embryos, indicating that, although these neuronal populations were correctly specified, their progenitors did not generate the appropriate amount of neuronal offspring in the Dicerl cKO embryos. We therefore hypothesized that a failure of vMH neural progenitors to exit the cell cycle and to generate the correct numbers of neuronal progeny might contribute to the loss of $\mathrm{vMH}$ neural tissues in the mutant embryos. To test this hypothesis, we injected EdU into pregnant dams at E11.5, $24 \mathrm{~h}$ before killing these mice. Colabeling for EdU and Ki67 (a marker for proliferating cells in all phases of the cell cycle) showed that the ratio of EdU/Ki67 double-positive cells per total number of EdU ${ }^{+}$cells (i.e., cells that 

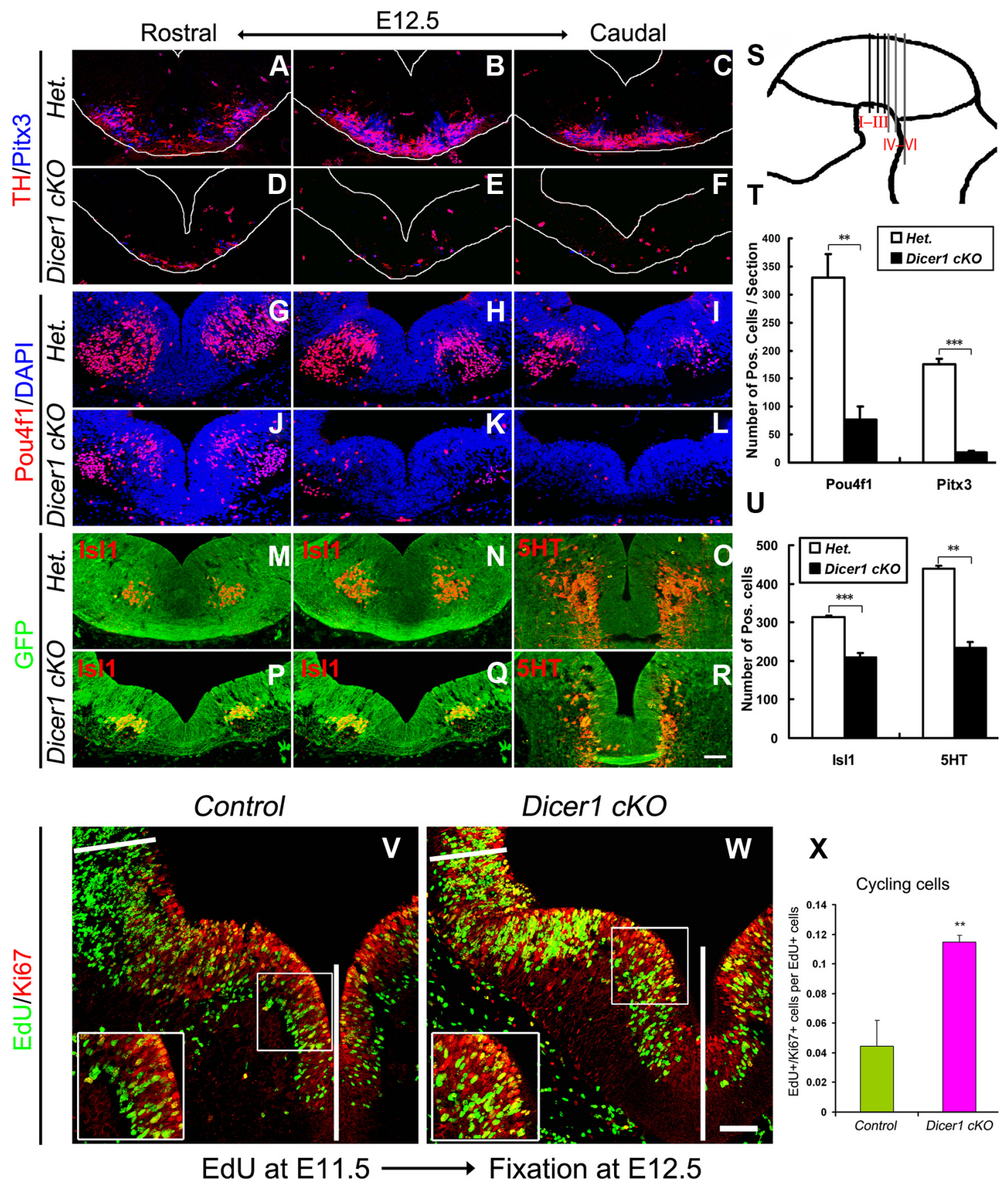

EdU at E11.5

Figure 3. Correct specification but reduced size of vMH neuronal populations attributable to cell-cycle exit defects in the Dicer 1 cKO embryos. $A-L, T$, The numbers of Pitx $3^{+}$(blue)/TH ${ }^{+}$(red) $\mathrm{mDA}$ and Pou $4 \mathrm{f}^{+}{ }^{+}$(red) RN neurons were drastically reduced in the ventral midbrain of E12.5 Dicer1 cKO embryos compared with their heterozygote (Het.) littermates (Pitx ${ }^{+}$cells: Het., $175.89 \pm$ 9.34; Dicer1 CK0, $17.89 \pm 3.42 ;$ Pou4f1 ${ }^{+}$cells: Het., $330.67 \pm 41.79 ;$ Dicer1 $C K 0,76.89 \pm 22.87 ; n=3 ;{ }^{* *} p<0.005,{ }^{* * *} p<0.001$, independent-samples $t$ test). The rostrocaudal position of the sections is depicted in $\mathbf{S}$ by $\mathrm{I}-\mathrm{III}$. White lines outline the neuroepithelium. $\boldsymbol{M}-\boldsymbol{R}, \boldsymbol{U}$, The numbers of Is $11^{+}$(red) $0 \mathrm{M}$ neurons in the ventral midbrain and of 5 -HT ${ }^{+}$(red) neurons in the ventral rostral hindbrain [mapped by En1 $1^{+/ / r e}$-mediated recombination of the CAG-CAT-EGFP reporter allele and consequent GFP (green) expression] were diminished in E12.5 Dicer1 CKO; CAG-CAT-EGFP embryos compared with their heterozygote (Het.) littermates (Is $11^{+}$cells: Het., $314.33 \pm 4.1$; Dicer1 cKO, $210 \pm 10.8 ; 5-\mathrm{HT}^{+}$cells: Het., $439 \pm 7.22 ;$ Dicer1 $c K 0,233 \pm 16.74 ; n=3 ;{ }^{* *} p<0.005$, ${ }^{* *} p=0.001$, independent-samples $t$ test). The rostrocaudal position of the sections is depicted in $\boldsymbol{S}$ by IV-VI. $\boldsymbol{V}-\boldsymbol{X}$, Double labeling for EdU (green) (injected at E11.5, $24 \mathrm{~h}$ before fixation of the embryos at E12.5) and Ki67 (red) revealed a significant increase of EdU ${ }^{+} / K_{i 67}{ }^{+}$double-positive cells per total EdU ${ }^{+}$cells (fraction of cell-cycle reentry) in the ventral MHR of the Dicer1 cKO embryos [Control (Het. and WT): $0.0444 \pm 0.0175$; Dicer1 $c K 0: 0.1147 \pm 0.0046 ; n=3 ;{ }^{* *} p<0.005$, independent-samples $t$ test). White lines delimit the area that was used for quantification of EdU/Ki67 single- and double-positive cells; insets are higher magnifications of the boxed areas in $\boldsymbol{V}$ and $\boldsymbol{W}$. Scale bar, $50 \mu \mathrm{m}$.

remain in the cell cycle) was remarkably increased by $\sim 2.6$-fold in the Dicer 1 KKO embryos (Fig. $3 \mathrm{~V}-\mathrm{X}$ ). We concluded that vMH neural progenitors fail to exit the cell cycle and thus to generate the proper amount of postmitotic progeny that can differentiate into $\mathrm{mDA}, \mathrm{OM}, \mathrm{RN}$, and 5-HT neurons in the Dicer1 cKO embryos, thereby contributing to the tissue loss in the absence of a strongly increased cell death in this region of the mutant brain.
miR-200 family members are strongly downregulated in the MHR of the Dicer1 cKO mice

miRNAs have been implicated in the regulation of cell proliferation, cell death, and neuronal differentiation in the CNS (Coolen and Bally-Cuif, 2009), but their role in the control of cell-cycle exit of neural progenitors is less well established. To find candidate miRNAs that might target known regulators of cell-cycle 


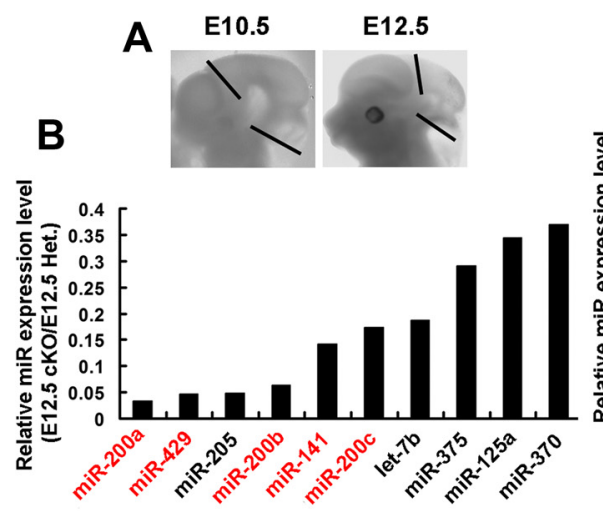

C

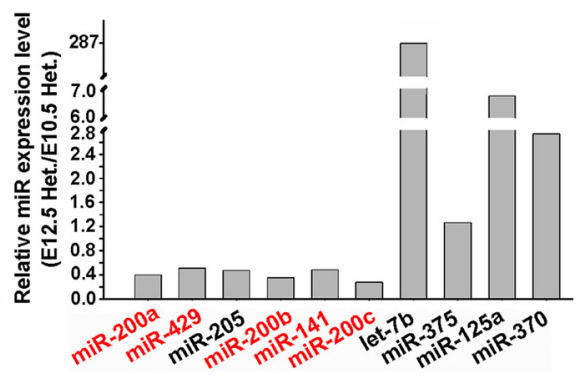

D
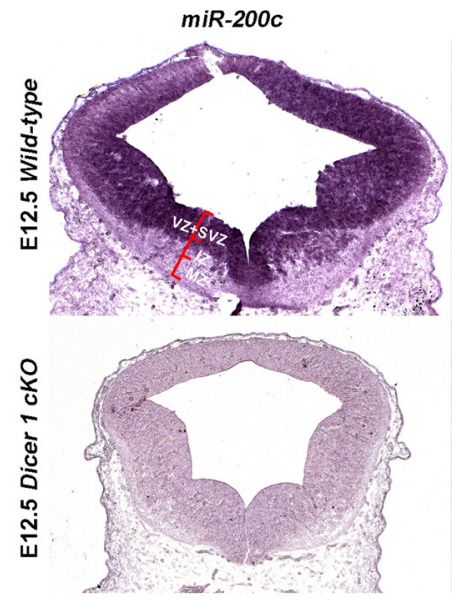

E

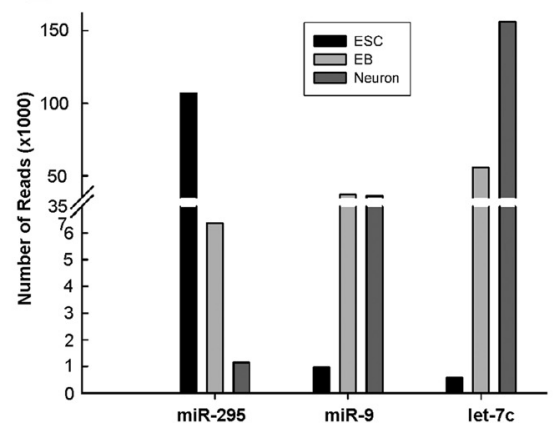

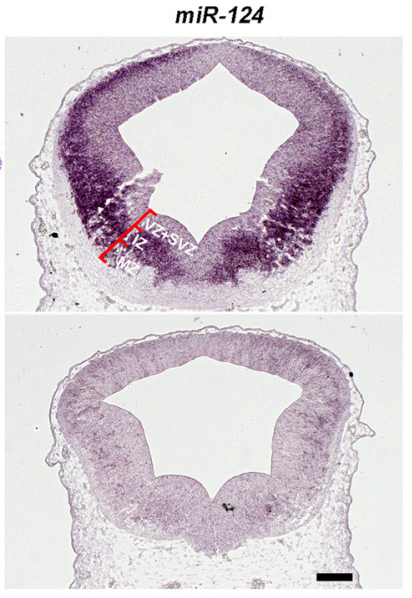

F

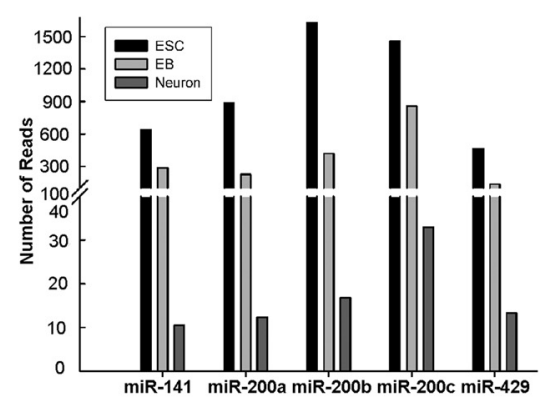

Figure 4. Loss of miR-200 family members in the MHR of Dicer1 CKO embryos. $\boldsymbol{A}$, The caudal diencephalon, mesencephalon, and rostral rhombomere 1 (delimited by black lines) was dissected from E10.5 and E12.5 wild-type and Dicer 1 cKO embryos and used for NGS miRNA profiling. $\boldsymbol{B}$, The five miR-200 family members (miR-200a, miR-429, miR-200b, miR-141, and miR-200c, highlighted in red) were among the top 10 most downregulated miRNAs in the MHR of the Dicer1 CKO embryos compared with the En1 ${ }^{+/ C r e}$;

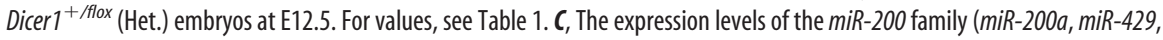
miR-200b, miR-141, and miR-200c, highlighted in red) in En1 ${ }^{+/ C r e}$; Dicer1 ${ }^{+/ f l o x}$ (Het.) embryos were strongly downregulated in the MHR at E12.5 compared with E10.5. For values, see Table 1. D, miR-200c is expressed in the VZ, SVZ, and IZ of the MH neuroepithelium in a complementary pattern to miR-124, which is strongly expressed in the IZ and MZ. miR-200c has a similar expression pattern in the forebrain and hindbrain (data not shown). Expression of miR-200c and miR-124 was abolished in the Dicer1 cKO embryos at E12.5. Scale bar, $100 \mu \mathrm{m}$. E, NGS profiling of miRNAs expressed during the directed differentiation of mESCs into neurons according to the protocol by Bibel et al. (2007). Known ESCC miRNAs (miR-295) or neural-specific miRNAs (miR-9 and let-7c) were selectively enriched in the corresponding steps of the differentiation procedure. $\boldsymbol{F}$, Expression of all five miR-200 family members was highest in undifferentiated mESCs and decreased to lowest levels in differentiated neurons. Neuron, Differentiated neurons.

progression and neural progenitor maintenance, we first determined the miRNA expression profile in the MHR (also including some wild-type tissue beyond the En ${ }^{+}$domain; Fig. $4 A$ ) of the E12.5 Dicer1 cKO embryos compared with their En1 ${ }^{+/ C r e}$; Dicer $1^{+/ \text {flox }}$ heterozygous littermates, using next generation sequencing (NGS) technology. Among the most strongly down- regulated miRNAs in the mutant MHR were the five members of the miR-200 family $(m i R-200 a / b / c, 141$, and 429; Fig. $4 B)$. The $m i R-200$ family was also expressed at lower levels in the MHR of En $1^{+/ \text {Cre }} ;$ Dicer $^{+/ \text {flox }}$ heterozygous embryos at E12.5 compared with E10.5, whereas let-7b and miR-125a, two members of the let-7 and miR-125 families promoting neuronal differentiation (Coolen and Bally-Cuif, 2009), were strongly upregulated in the MHR of the E12.5 compared with the E10.5 heterozygous embryos (Fig. 4C), suggesting that the expression of the $m i R-200$ family declines with the progression of neuronal differentiation in the MHR. Based on our NGS data (Fig. 4B, Table 1), $m i R-200 c$ still showed the highest expression levels in the mutant MHR relative to the other miR-200 family members at E12.5, and we therefore detected this miRNA in wildtype and Dicer 1 cKO embryos using LNAbased ISH. In the E12.5 wild-type embryo, $\mathrm{miR}-200 \mathrm{c}$ is strongly expressed in the ventricular (VZ), subventricular (SVZ), and intermediate (IZ) zones but not in the mantle zone (MZ) of the MH neuroepithelium (Fig. 4D). The expression of miR-200c was complementary to the transcription of the neuron-specific miR-124 (Coolen and Bally-Cuif, 2009) in the IZ and MZ of the E12.5 wild-type embryo (Fig. 4D). Notably, $m i R-200 c$ was undetectable and $m i R-124$ was barely detectable in the MHR of the $D i$ cer1 cKO embryos at E12.5 (Fig. 4D), thus validating our NGS approach and confirming the near-complete ablation of mature miRNAs in the MHR of the E12.5 Dicer1 cKO embryos.

The miR-200 family members might be generally implicated in the regulation of cell proliferation, cell-cycle exit, and differentiation of pluripotent/multipotent stem cells, including neural stem/ progenitor cells (Peter, 2009). To establish whether this is the case, we used an in vitro paradigm to differentiate mESCs into Tubb3 ${ }^{+}$postmitotic neurons (Bibel et al., 2007) and determined the miRNA profile in these cells at three different stages of the differentiation protocol: mESCs representing the initial pluripotent state, EBs representing neuroectodermal commitment, and postmitotic neurons representing the differentiated neuron state. Known miRNAs were enriched at the expected stages of the differentiation procedure (Fig. $4 E$ ), such as the ESCC miR-295 in the undifferentiated mESC stage (Wang et al., 2008; Martinez and Gregory, 2010), miR-9 in the committed neuroectodermal and differentiated neuron stage, and $l e t-7 c$ in the differentiated neuron stage (Krichevsky et al., 2006; Coolen and Bally-Cuif, 2009), thus validating our approach. Consistent 
with a previous report (Gill et al., 2011), expression of the miR200 family was highest in undifferentiated mESCs; their expression levels decreased to an intermediate level in committed neuroectodermal cells and dropped to their lowest levels $(\sim 30$ to 100 -fold lower than in the mESCs) in the differentiated neurons (Fig. $4 F$ ). Notably, $m i R-200 c$ still showed the highest expression level in differentiated neurons among all $m i R-200$ family members (Fig. $4 F$ ). We concluded that the $m i R-200$ family members are highly expressed in undifferentiated pluripotent/multipotent stem/progenitor cells and that their expression levels decline along the commitment and differentiation of these cells into neurons both in vivo and in vitro. Their strong downregulation in the MHR of the Dicer 1 cKO embryos might thus contribute to the defective cell-cycle exit and differentiation of $\mathrm{vMH}$ neural progenitors observed in these mutants.

\section{Sox ${ }^{+}$and $\mathrm{E} 2 \mathrm{~F}^{+}{ }^{+}$neural progenitor cells accumulate in the MHR of the Dicer1 cKO embryos}

We next searched for possible targets of the miR-200 family whose deregulation in $\mathrm{MH}$ tissues might cause the cell-cycle defects observed in the Dicer 1 cKO embryos. Two of the predicted targets of the $m i R-200$ family using bioinformatics tools (Targetscan; http://www.targetscan.org) are the TFs Sox2 and E2F3. Sox2 is required for the maintenance of self-renewing neural stem/progenitor cells (Graham et al., 2003; Pevny and Nicolis, 2010), and E2F3 plays a pivotal role in cell-cycle progression, particularly in promoting the S-phase entry of proliferating cells (Leone et al., 1998; DeGregori, 2002). Both TFs were expressed in the MHR of E12.5 wild-type mice within the same domain as $m i R-200 c$ : Sox 2 expression was confined to the neural progenitors in the VZ/SVZ, whereas E2F3 was expressed in single cells that extended from the VZ/SVZ into the IZ of the ventral MHR and spared the cell layer immediately adjacent to the third ventricle (Fig. 5A). Because the Sox ${ }^{+}$and E2F3 ${ }^{+}$cells appeared to be increased in the ventral MHR of the Dicer 1 cKO embryos (Fig. $5 A$ ), we hypothesized that these two TFs might indeed be direct targets of the miR-200 family in vMH neural progenitors.

To establish this in more detail, we determined the numbers of Sox $2^{+}, \mathrm{E} 2 \mathrm{~F}^{+}{ }^{+}$, and proliferating S-phase $\left(\mathrm{EdU}^{+}\right)$cells in the MHR of the mutant embryos compared with their wild-type littermates. We focused our analyses on the ventral MHR because this was the region where we had previously detected the cellcycle exit defects in the Dicer 1 cKO embryos and because of the massive cell death in the mutant dorsal MHR from E11.5 onward. At E10.5, the Sox ${ }^{+}$domain was not obviously altered, but the $\mathrm{Tubb}^{+}$postmitotic neuron domain was clearly reduced in the ventral MHR of the Dicer 1 cKO embryos (Fig. 5B), indicating that the differentiation of neural progenitors into postmitotic neurons was affected in the mutant embryos at or even before E10.5. At E11.5, the Sox ${ }^{+}$domain was visibly expanded at the expense of the Tubb3 ${ }^{+}$domain (Fig. $5 B$ ), and the numbers of Sox $2^{+}$, $\mathrm{E}^{2} \mathrm{F3}^{+}\left(\mathrm{G}_{1} / \mathrm{S}\right.$-phase), and EdU ${ }^{+}$(S-phase) neural progenitors were increased by $25 \%\left(\right.$ Sox $2^{+} / \mathrm{E} 2 \mathrm{~F}^{+}$cells) and $18 \%\left(\mathrm{EdU}^{+}\right.$ cells) in the ventral MHR of the Dicer1 cKO embryos (data not shown). At E12.5, the numbers of Sox $2^{+}, \mathrm{EdU}^{+}$, and E2F3 ${ }^{+}$ neural progenitor cells were increased by 1.7 - to 1.9 -fold, and the thinning of the Tubb3 ${ }^{+}$domain became even more evident in the ventral MHR of the Dicer1 cKO embryos (Fig. 5C,D,F). The increase of Sox ${ }^{+}$cells was attributable to the enlargement of the Sox $2^{+}$area and not an increase of Sox $2^{+}$cell density in the mutant embryos (Fig. 5E). Remarkably, the proportion of EdU ${ }^{+}$ (S-phase) cells that coexpressed E2F3 (EdU/E2F3 doublepositive cells per total amount of EdU ${ }^{+}$cells) and the number of
EdU/E2F3 double-positive cells were increased by $80 \%$ and twofold, respectively, in the ventral MHR of the Dicer 1 cKO embryos compared with their wild-type littermates at E12.5 (Fig. 5G). The expansion of the proliferating Sox $2^{+}$and E2F3 ${ }^{+}$neural progenitor domain in the ventral MHR of the Dicer 1 cKO embryos was accompanied by an apparent change of $\mathrm{vMH}$ morphology and mediolateral expansion of the cavity of the third ventricle in the mutant embryos (Fig. 5A-C). Altogether, our results indicated that proliferating $\left(\mathrm{EdU}^{+} / \mathrm{Sox} 2^{+} / \mathrm{E} 2 \mathrm{~F} 3^{+}\right)$neural progenitors accumulate over time in the ventral MHR of the Dicer1 cKO embryos, suggesting that their failure to exit the cell cycle and to generate the proper amount of Tubb3 ${ }^{+}$neuronal progeny was attributable to their inability to downregulate Sox 2 and in particular E2F3 protein levels in the absence of $m i R-200$ miRNAs.

\section{miR-200 miRNAs promote the neuronal differentiation of vMH neural progenitors}

Our results so far suggested that the $m i R-200$ family might regulate the cell-cycle exit and neuronal differentiation of vMH neural progenitors by targeting the expression of Sox 2 and E2F3 in these cells. To establish this more conclusively, we generated an $m i R$ $200 \mathrm{OE}$ vector for the constitutive expression of $m i R-200$ family members in primary cultures derived from the ventral MHR of E11.5 wild-type mice. We focused on the $m i R-200 c / 141$ cluster (located on chromosome 6 in the mouse), because this cluster represents both seed sequence subgroups (that differ by just $1 \mathrm{nt}$ ) of the $m i R-200$ family with potentially different target mRNAs (Peter, 2009; Uhlmann et al., 2010). Overexpression of the $m i R$ $200 c / 141$ cluster under the control of the U6 promoter ( $p U 6-$ $m i R-200 c-141-C A G-E G F P$ OE vector or OE-miR-200 vector; Fig. $6 A$ ) resulted in a moderate increase (between 1.3- and 2.7fold) of $m i R-200 c$ and $m i R-141$ levels in the transfected cells (Fig. $6 B)$. Cotransfection of the OE-miR-200 vector with a Sox $23^{\prime} U T R$ sensor vector containing one $m i R-200 c$ BS showed that this vector was able to repress the expression of luciferase from the sensor vector (Fig. 6C). Overexpression of $m i R-200 c / 141$ in primary vMH cultures led to a significant reduction of Sox $2^{+}$and E2 $\mathrm{F} 3^{+}$ neural progenitor cells and to a significant increase of Tubb3 ${ }^{+}$ postmitotic neurons at $3 \mathrm{dpt}$ (Fig. $6 D-G$ ). Transfection of an $m m u$ - $m i R-200 c$ pre-miRNA into primary vMH cultures also resulted in a strong reduction of Sox 2 and E2F3 and an increase of Tubb3 protein levels in these cultures compared with the controltreated cultures (Fig. $6 \mathrm{H}$ ). These data show that the overexpression of $m i R-200$ family members indeed promotes the neuronal differentiation of $\mathrm{vMH}$ progenitor cells by downregulating the expression of Sox 2 and E2F3 in these cells.

We next investigated whether the knockdown of the miR-200 family in primary vMH cultures leads to the opposite effect, i.e., reduced neuronal differentiation of $\mathrm{vMH}$ progenitor cells, thereby mimicking the phenotype observed in the ventral MHR of the Dicer 1 cKO embryos. To test this, we generated an $m i R-200$ sponge vector (Ebert et al., 2007) containing eight repeats of a fully complementary sequence to all five $m i R-200$ family members inserted downstream of the EGFP CDS and driven by the $C A G$ promoter (Fig. 7A). The functionality of this sponge vector was tested by cotransfecting this vector together with the OE$m i R-200$ vector and a Sox $23^{\prime} U T R$ sensor vector into COS-7 cells. The reduction of luciferase expression from the sensor vector after cotransfection of the OE-miR-200 vector was in fact abolished (rescued) by the cotransfected $m i R-200$ sponge vector (Fig. $7 B)$. Because primary vMH cells express rather low levels of $m i R$ $200 c$ compared with the ubiquitously expressed U6B snRNA (Fig. $7 C$ ), we expected that transfection of the $m i R-200$ sponge vector 
A

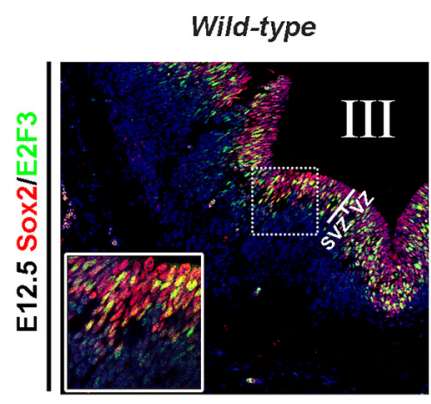

C

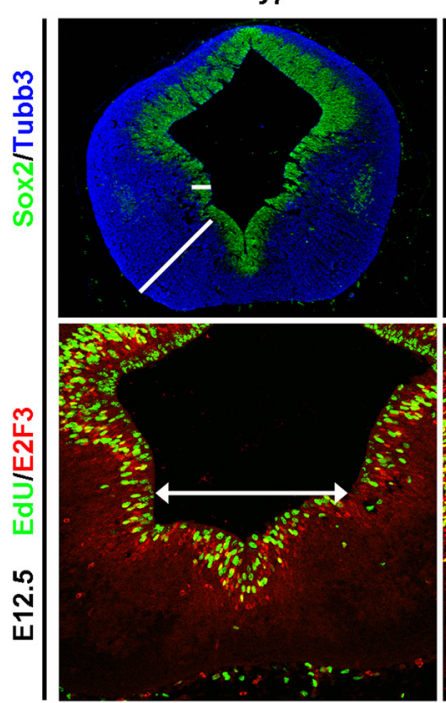

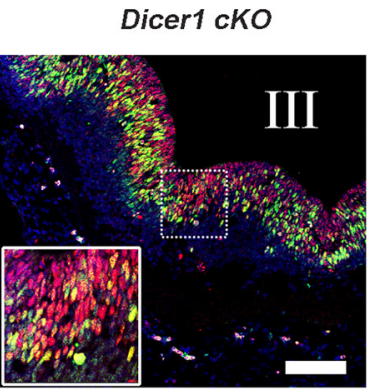

Dicer1 cKO

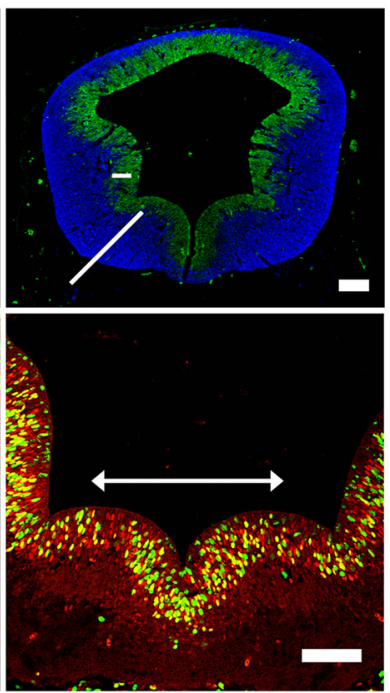

B

E10.5

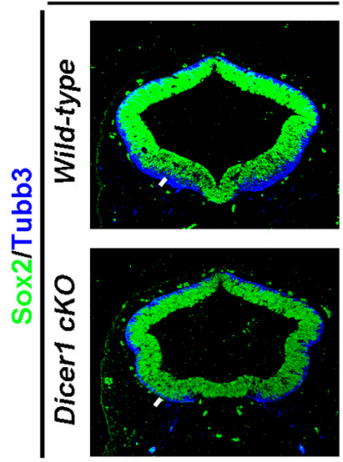

E11.5

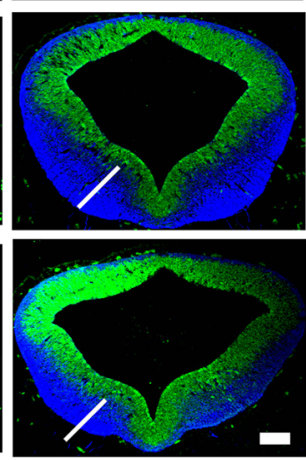

E12.5 ***
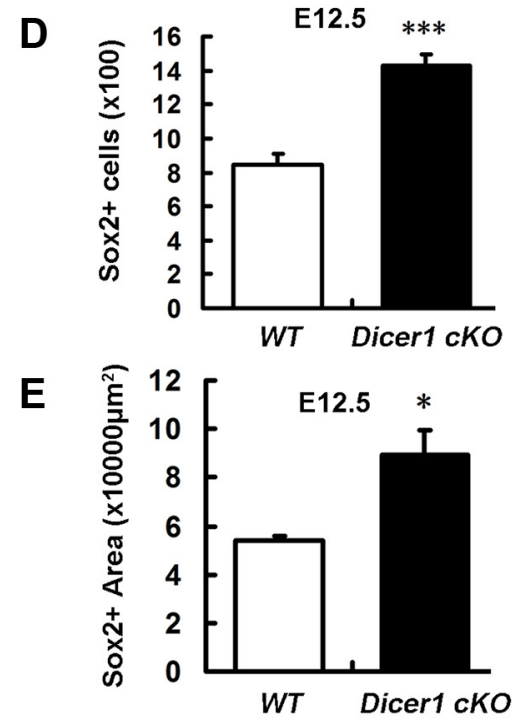

F

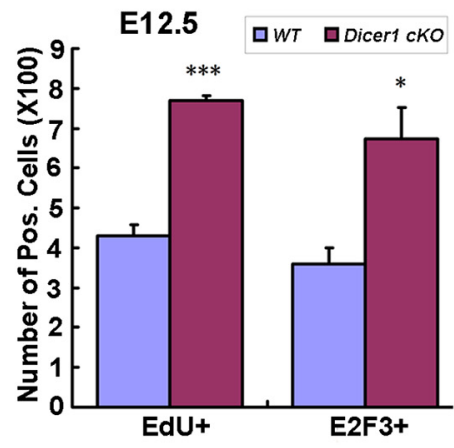

E12.5

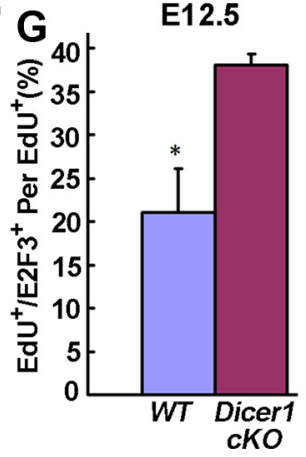

Figure 5. Accumulation of proliferating Sox $2^{+} / \mathrm{ELF}^{+}{ }^{+}$neural progenitors and reduced neuronal differentiation in the ventral MHR of the Dicer $1 \mathrm{CKO}$ embryos. A, The predicted miR-200c targets Sox 2 and E2F3 are expressed in the VZ/SVZ and IZ of the MH neuroepithelium. E2F3 is expressed in single cells sparing the layer immediately adjacent to the third ventricle (III). Pictures are taken from adjacent sections to the ones shown in Figure 4D.B, Reduced thickness [white lines correspond to wild-type(WT) embryos] of the Tubb ${ }^{+}{ }^{+}$(blue) postmitoticneuron layer and expansion of the Sox ${ }^{+}$(green) cell layer in the ventral MHR of the Dicer1 CKO embryos at E10.5 and E11.5. C, E12.5 Dicer1 CKO embryos have an expanded Sox2 ${ }^{+}$(green in top row) and reduced Tubb3 ${ }^{+}$(blue) domain [white lines depict the thickness of the corresponding layer in wild-type (WT) embryos] and strongly increased numbers of $\mathrm{SOX2}^{+}, \mathrm{E} 2 \mathrm{~F}^{+}{ }^{+}$(red), and EdU ${ }^{+}$(green in bottom row) neural progenitor cells in the ventral MHR. Note the mediolateral broadening of the ventricular cavity in the ventral MHR of the Dicer1 cKO embryos (white double arrows). D-F, Quantification of Sox2 ${ }^{+}$, EdU ${ }^{+}$, and E2F3 ${ }^{+}$cells in the Dicer1 $c K 0$ embryos atE12.5. [Sox2 ${ }^{+}$cells (D):WT, 845.75 \pm 67.45; Dicer1 CKO, $1433 \pm 59.16 ; * * * p=0.001 ;$ Sox2 ${ }^{+}$area (E):WT, 53,941.75 $\pm 1945 ;$ Dicer1 CKO,89,127.75 $\pm 10,292 ;{ }^{*} p<0.05 ; n=4 ;$ EdU ${ }^{+}$cells $(\boldsymbol{F}):$ WT, 430 $\pm 27.4 ;$ Dicer1 cKO, $770 \pm 10.6 ;{ }^{* * *} p<0.001 ; \mathrm{ELF3}^{+}$cells $(\boldsymbol{F}): \mathrm{WT}, 360 \pm 39.3 ;$ Dicer1 CKO,673 $\pm 78.5 ;{ }^{*} p<0.05 ; n=3$, statistical significance was estimated by independent-samples $t$ test.] G, The number of $\mathrm{FdU}{ }^{+} / \mathrm{E2F3}{ }^{+}$ double-labeled cells and their ratio per total amount of EdU ${ }^{+}$(S-phase) cells were strongly increased in the ventral MHR of theE12.5 Dicer1 cKO embryos [EdU ${ }^{+} / \mathrm{EZ}_{2} \mathrm{~F}^{+}{ }^{+}$cell numbers: WT, $96 \pm 23.4 ;$; Dicer1 cKO, $293.7 \pm 13.3 ; \mathrm{EdU}^{+} / \mathrm{EZF}^{+}{ }^{+}$per EdU ${ }^{+}$cells (\%):WT, $21 \pm 5.1 ;$ Dicer1 CKO,38.1 $\pm 1.2 ; n=3,{ }^{*} p<0.05$ independent-samples $\left.\mathrm{ttest}\right]$. Scale bars: $\boldsymbol{A}-\boldsymbol{C}, 100 \mu \mathrm{m}$.

would fully knock down the miR-200 family in these cells. Indeed, the numbers of Sox ${ }^{+}$and $\mathrm{E} 2 \mathrm{~F} 3^{+}$neural progenitor cells were increased, and the numbers of Tubb $3^{+}$postmitotic neurons were decreased after transfection of the $m i R-200$ sponge vector compared with the control-transfected primary vMH cells (Fig. $7 D-G$ ), thus phenocopying the ventral MHR defects of the Dicer1 cKO embryos
(Fig. 5). In summary, our data strongly support the idea that the miR-200 family is required to promote the cell-cycle exit and neuronal differentiation of proliferating vMH neural progenitors by targeting the expression of Sox2 and E2F3 in these cells and that the ventral MHR phenotype of the Dicer1 cKO mice is mainly caused by the loss of mature miR-200 miRNAs in these mutants. 


\section{A OE-miR-200 vector}

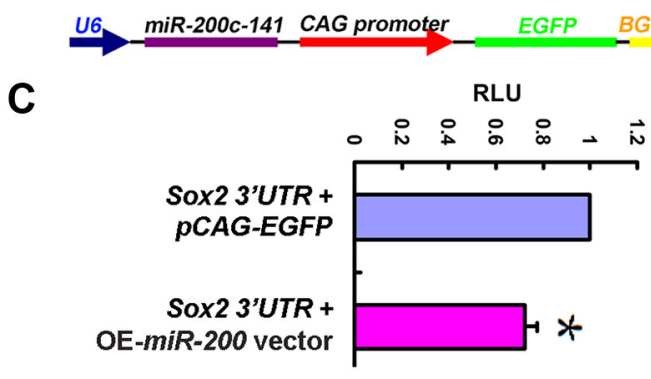

D

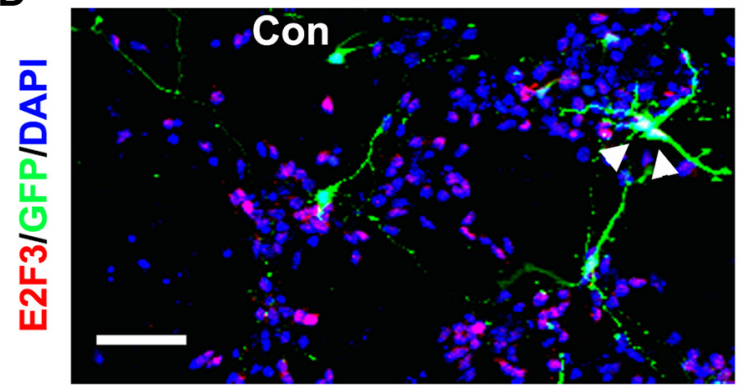

E

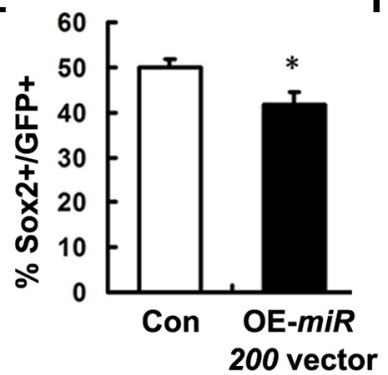

$\mathbf{F}$

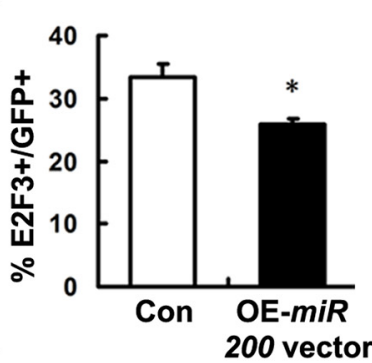

B

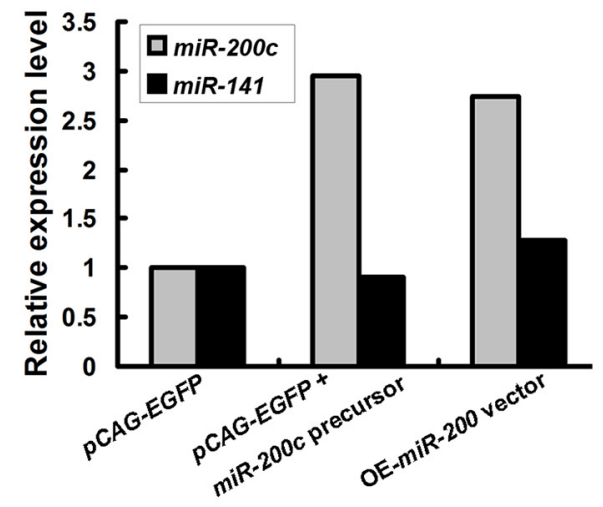

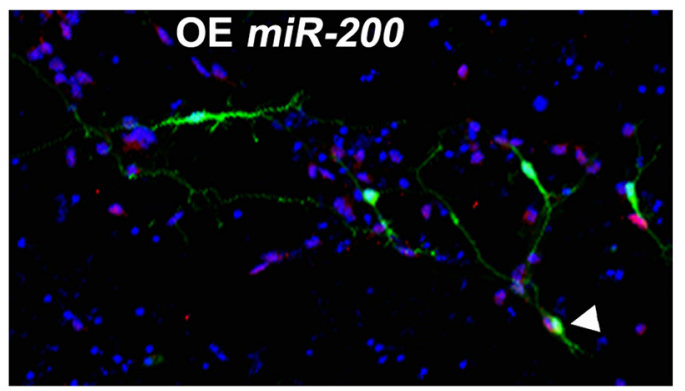

G

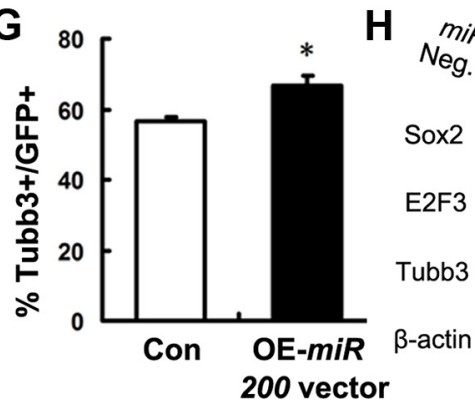

Figure 6. Overexpression of miR-200c-141 promotes neuronal differentiation of vMH neural progenitors in vitro. A, Schematic of the pU6-miR-200c-141-CAG-EGFP 0E vector (0E-miR-200 vector) used for all miR-200 0E experiments. Expression of the mmu-miR-200c-141 cluster was under control of an U6 promoter and was monitored by CAG promoter-driven EGFP expression. $\boldsymbol{B}$, Quantification of the miR-200c and miR-141 expression levels by qRT-PCR after cotransfection of pcDNA6.2-EmGFP ( $p$ CAG-EGFP) vector and the mmu-miR-200c precursor miRNA or after transfection of the OE-miR-200 vector into HEK-293 cells. Transfection of $p C A G-E G F P$ "empty" vector alone served as control, and this value was set as 1 . Cotransfection of $p C A G-E G F P$ and mmu-miR-200c precursor miRNA resulted in an increase of only miR-200c but not of miR-141 expression, demonstrating the specificity of the qRT-PCR detection assay. A modest (1.3- to 2.7-fold) increase of miR-200c and miR-141 expression levels was detected after transfection of the 0E-miR-200 vector. C, Functional validation of the 0E-miR-200 vector. Cotransfection of the $p G L 3-S 0 x 2-$ $3^{\prime}$ UTR sensor vector and OE-miR-200 vector in COS-7 cells resulted in a significant repression of luciferase expression from the sensor vector. Cotransfection of $p G L 3-$ Sox2-3' UTR sensor and pCAG-EGFP "empty" vector served as control, and this value was set as 1. ( $p G L 3-S o x 2-3^{\prime}$ UTR +0 E-miR-200 vector: $0.722 \pm 0.054, n=3$; ${ }^{*} p<0.05$, statistical significance was estimated by paired-samples $t$ test). RLU, Relative luciferase units. D, Overexpression of miR-200c-141 caused a decrease of Sox2 ${ }^{+}$(data not shown) and E2F3 ${ }^{+}$(red) neural progenitor cells and an increase of $\mathrm{Tubb3}^{+}$(data not shown) postmitotic neurons in E11.5 primary vMH cultures transfected with the 0E-miR-200 vector [GFP ${ }^{+}$(green) cells]. Transfection of $p$ CAG-EGFP"empty" vector alone served as control (Con). White arrowheads point at E2F3 ${ }^{+}$and GFP ${ }^{+}$double-labeled cells. Scale bar, $50 \mu \mathrm{m}$. $\boldsymbol{E}-\mathbf{G}$, Quantification of Sox2 ${ }^{+}(\boldsymbol{E}), \mathrm{E} 2 \mathrm{~F} 3^{+}(\boldsymbol{F})$, and Tubb3 $^{+}(\boldsymbol{G})$ transfected $\left(\mathrm{GFP}^{+}\right)$primary

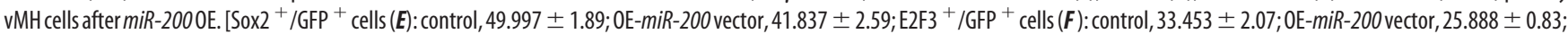
$\mathrm{Tubb}^{+} /{ }^{+} \mathrm{GFP}^{+}$cells (G): control,56.504 $\pm 1.12 ; 0 \mathrm{E}$-miR-200 vector, $66.639 \pm 2.67 ; n=4 ;{ }^{*} p<0.05$, independent-samples $t$ test). $\boldsymbol{H}$, Transfection of $m$ mu-miR-200c precursor miRNA in primary vMH cells strongly downregulated Sox2 and E2F3 and upregulated Tubb3 protein levels in these cells compared with cells transfected with a negative control precursor miRNA (Neg. control).

Sox 2 and E2F3 mRNAs are direct targets of $m i R-200 c$

Given the strong correlation between the overexpression or downregulation of $m i R-200$ miRNAs and the decrease or increase of Sox ${ }^{+}$and $\mathrm{E} 2 \mathrm{~F} 3{ }^{+}$cells, respectively, in vivo and in vitro, we next determined whether Sox 2 and E2F3 mRNAs are direct targets of the miR-200 family. Using bioinformatics prediction tools (http://www.targetscan.org), we found that there is one conserved (among vertebrates) BS for the $m i R-200 b / c / 429$ seed sequence subgroup within the mouse Sox $23^{\prime} U T R$ and four conserved (in mammals) BSs for the $m i R$-200 family (two BSs for each seed sequence subgroup) within the mouse E2F3 $3^{\prime} U T R$ (Fig. 8A,B). We therefore cloned the mouse Sox2 3'UTR (containing the single $m i R-200 c \mathrm{BS}$ ) or E2F3 $3^{\prime}$ UTR (containing two $m i R-200 c$ BSs) into a luciferase reporter (sensor) vector and cotransfected these vectors together with an $m m u-m i R-200 c$ precursor miRNA into COS-7 cells. The miR-200c pre-miRNA repressed the luciferase expression from the Sox2 $3^{\prime} U T R$ sensor vector by $\sim 50 \%$ and from the E2F3 $3^{\prime} U T R$ sensor vector by $\sim 30 \%$ (Fig. 8C,D). To confirm this result, we cotransfected the pcDNA6.2-EmGFP-miR-200c OE vector together with the sensor vectors into COS-7 cells. Luciferase expression was decreased by $\sim 26 \%$ (Sox2 3'UTR) and $\sim 33 \%$ (E2F3 3'UTR) after $m i R-200 c$ overexpression, and this repression was abolished after site-directed mutagenesis of the conserved $m i R-200 c$ BSs in the sensor vectors (Fig. $8 A, B, E, F)$. Notably, the luminescence values after sitedirected mutagenesis of the conserved $m i R-200 c$ BSs were even 


\section{A Sponge miR-200 vector}

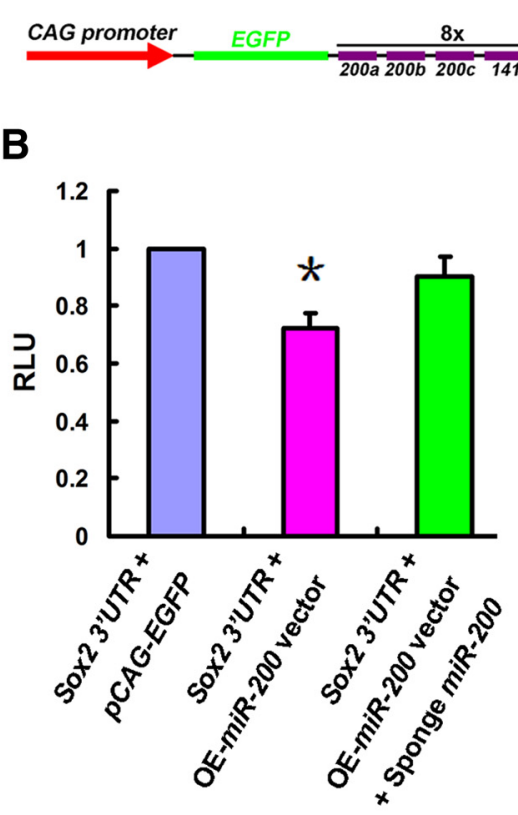

C $=-$ BGH poly $A$

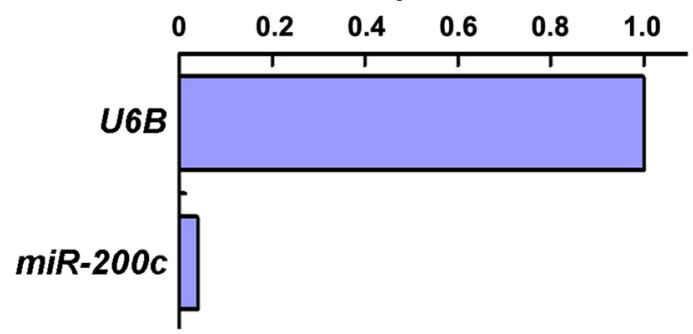

D
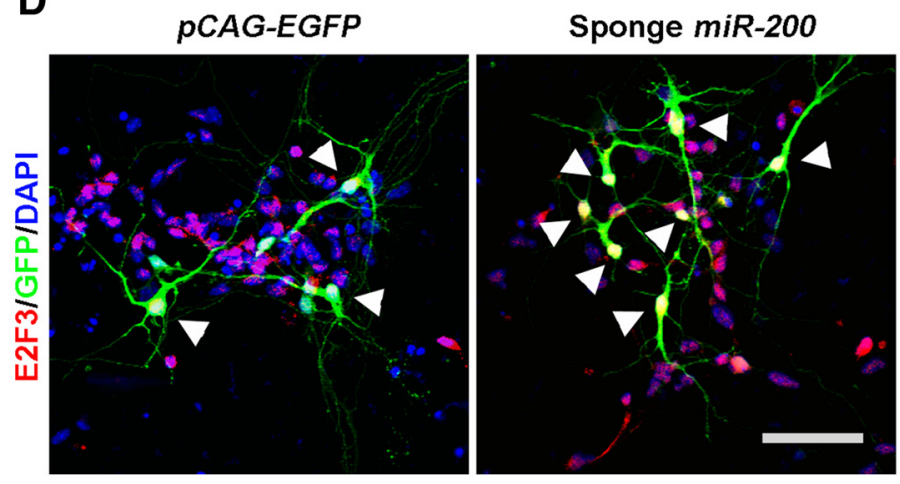

E

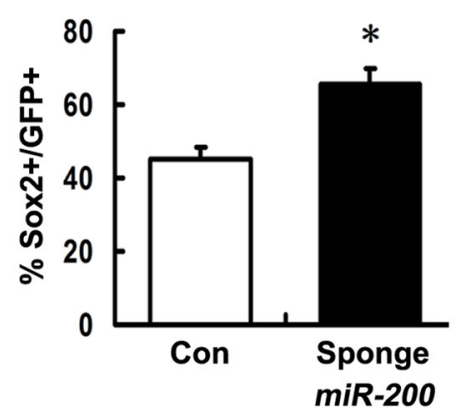

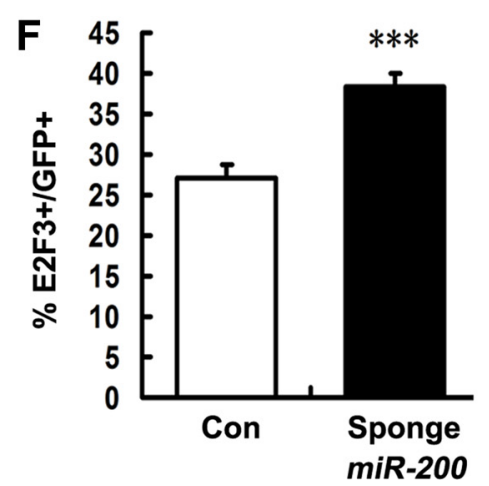

G

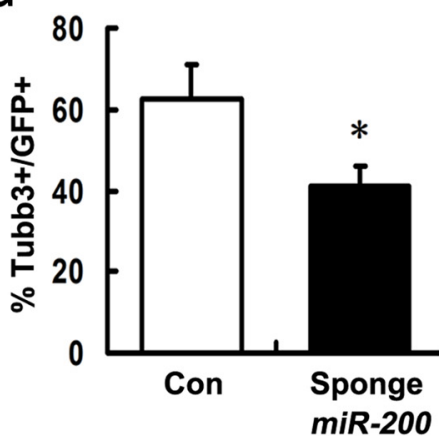

Figure 7. Knockdown of the miR-200 family suppresses neuronal differentiation of vMH neural progenitors in vitro. $\boldsymbol{A}$, Schematic of the sponge miR-200 vector. Eight repeats of fully complementary sequences to all five mmu-miR-200 family members were inserted downstream of the CAG promoter-driven EGFP CDS in the sponge vector. $\boldsymbol{B}$, Cotransfection of the $p G L 3-S 0 x 2-3^{\prime}$ UTR sensor vector, $0 \mathrm{E}-$-miR-200 vector, and sponge miR-200 vector in COS-7 cells significantly rescued the luciferase expression from the sensor vector to similar levels as after cotransfection of sensor and pCAG-EGFP (control) vectors (value was set to 1) and compared with the cotransfection of sensor and 0E-miR-200 vectors alone (see Fig. 6C). ( $p$ GL3-Sox2-3' UTR + 0E-miR-200 vector + sponge miR-200 vector: $0.903 \pm 0.069, n=3,{ }^{*} p<0.05$, statistical significance was estimated by paired-samples $t$ test). RLU, Relative luciferase units. C, Quantification of endogenous miR-200c levels in primary vMH cultures after $4 \mathrm{~d}$ in vitro by qRT-PCR. miR-200c expression levels are $1 / 25$ of the U6B snRNA levels in these cultures. $\boldsymbol{D}$, Knockdown of the miR-200 family in E11.5 primary vMH cells transfected with the sponge miR-200 vector [GFP ${ }^{+}$(green) cells] resulted in an increase of Sox2 ${ }^{+}$(data not shown) and E2F3 ${ }^{+}$(red) neural progenitor cells and a decrease of Tubb3 ${ }^{+}$(data not shown) postmitotic neurons. Transfection of $p$ CAG-EGFP "empty" vector alone served as control (Con). White arrowheads point to E2F3 ${ }^{+}$and GFP ${ }^{+}$double-labeled cells. Scale bar, $50 \mu \mathrm{m}$. $\boldsymbol{E}-\mathbf{G}$, Quantification of Sox2 ${ }^{+}(\boldsymbol{E}), \mathrm{E} 2 \mathrm{F3}^{+}(\boldsymbol{F})$, and Tubb3 ${ }^{+}(\boldsymbol{G})$ transfected $\left(\mathrm{GFP}^{+}\right)$primary vMH cells after miR-200 knockdown. [Sox2 ${ }^{+} / \mathrm{GFP}^{+}$cells $(\boldsymbol{E})$ : control, $44.928 \pm 3.25 ;$ sponge miR-200 vector, $65.511 \pm 4.16 ; \mathrm{E} 2 F 3^{+} / \mathrm{GFP}^{+}$cells $(\boldsymbol{F})$ : control, $27.183 \pm 1.67 ;$ sponge miR-200 vector, $38.255 \pm 1.82 ;$ Tubb3 $^{+} / \mathrm{GFP}^{+}$cells $(\boldsymbol{G}):$ control, $62.63 \pm 8.6 ;$ sponge miR-200 vector, $41.13 \pm 4.93 ; n=$ $3 ;{ }^{*} p<0.05,{ }^{* * *} p=0.001$, paired-samples $t$ test).

higher than in the control ( $p c D N A 6.2-E m G F P$ "empty" vector)transfected cells (Fig. $8 E, F$ ). This is most likely attributable to the repression of the sensor vectors by the endogenous expression of miR-200c in COS-7 cells (data not shown). Our results show that $m i R-200 c$ regulates the expression levels of Sox 2 and E2F3 by directly binding to conserved BS(s) within the 3'UTR of their mRNAs.

Sox 2 and E2F3 directly activate the $m m u-m i R-200 c / 141$ promoter

Although Sox 2 and E2F3 are direct targets of $m i R-200 c$, both TFs are coexpressed with $m i R-200 c$ in at least a subpopulation of vMH neural progenitors (Figs. $4 D, 5 A$ ). We therefore hypothesized that Sox 2 and E2F3 might in turn regulate the expression of the $m i R-200$ family in neural progenitor cells. To test this hypothesis, we first searched for conserved Sox 2 and E2F BSs within the
miR-200c/141 promoter region $(-2 \mathrm{~kb}$ to $+500 \mathrm{bp})$ using the Gene2promoter software (Genomatix). We then cloned the distal (Promoter 1) and proximal (Promoter 2) promoter region of the $m m u-m i R-200 c / 141$ cluster harboring several conserved Sox2 (sequence: AACAAAG) and/or E2F (core sequence: GCGC) BSs into a luciferase reporter vector (Fig. 9A). Cotransfection of this pGL3-mmu-miR-200c/141 reporter vector together with vectors encoding Sox2 or E2F3 into HEK-293 cells led to a 3- and 3.4-fold activation of the distal $m m u-m i R-200 c / 141$ promoter region (Promoter 1 containing conserved Sox 2 and E2F BSs) by E2F3 and Sox2, respectively, and to a fivefold activation of the proximal $m m u-m i R$ 200c/141 promoter region (Promoter 2 containing only conserved E2F BSs) by E2F3 (Fig. 9B). These data indicate that the transcription of the $m m u-m i R-200 c / 141$ gene cluster is in fact activated by Sox 2 and to an even greater extent by E2F3 TFs. Altogether, our data 

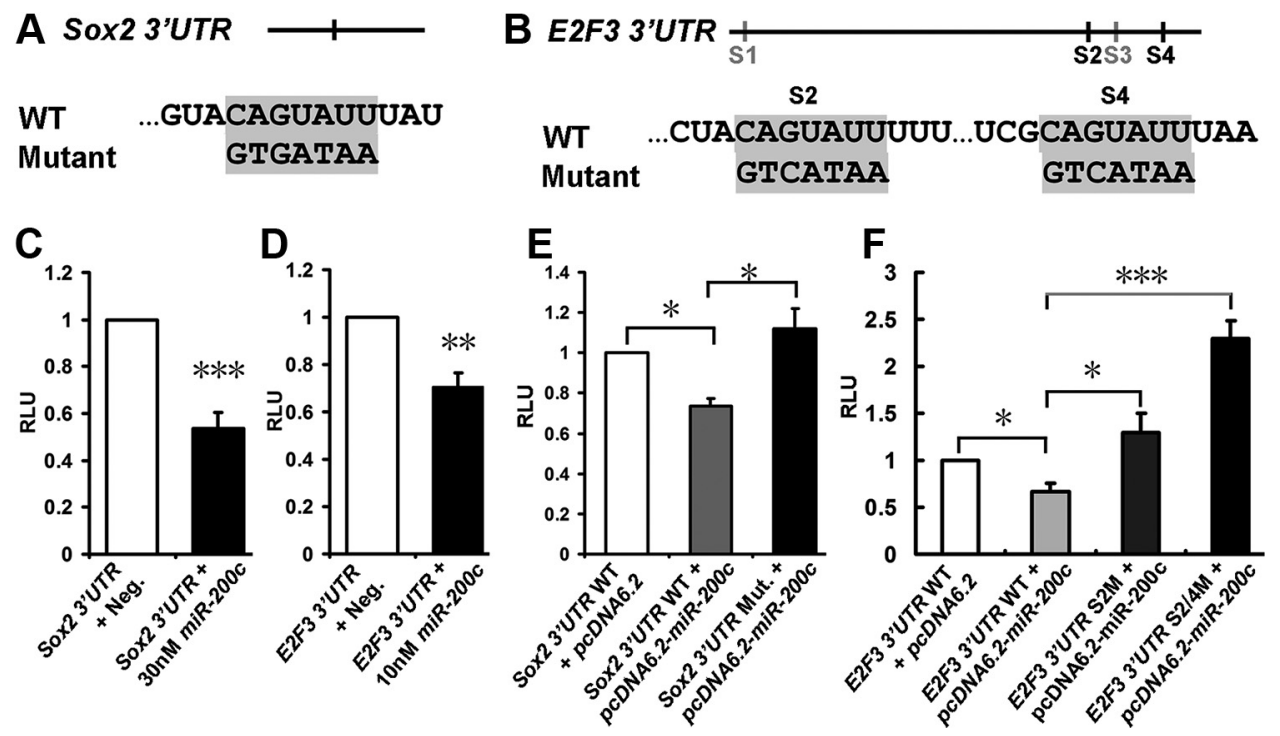

Figure 8. miR-200c targets directly the Sox2 and E2F3 3'UTRs. $A$, Top, Relative position of the conserved miR-200c/b/429 BS within the mouse Sox2 3'UTR. Bottom, Sequence of the wild-type (WT) and mutated (mutant) miR-200c/b/429 BS in the mouse Sox2 3'UTR. Seed regions/sequences are highlighted in gray. B, Top, Relative positions of four conserved (in mammals) BSs for the miR-200 family within the mouse E2F3 3'UTR. BS1 and BS3 (S1 and S3, gray bars) are complementary to the miR-200a/141 seed sequence, and BS2 and BS4 (S2 and S4, black bars) are complementary to the miR-200c/b/429 seed sequence. The E2F3 3'UTR containing S2-S4 was used for the sensor assays. Bottom, Sequence of the wild-type (WT) and mutated (mutant) miR-200c/b/429 BSs (S2 and S4) in the mouse E2F3 3'UTR. Seed regions/sequences are highlighted in gray. C, D, Transfection of $30 \mathrm{~nm}$ (Sox2) or $10 \mathrm{~nm}$ (E2F3) mmu-miR-200c precursor miRNA in COS-7 cells repressed the luciferase expression from the $p G L 3-S 0 x 2-3^{\prime}$ UTR and $p G L 3-E 2 F 3-3^{\prime}$ UTR sensor vectors compared with cells transfected with a negative control (Neg.) precursor miRNA (negative control value was set as 1; $30 \mathrm{~nm}$ mmu-miR-200c precursor + Sox23'UTR: $0.538 \pm 0.068 ; 10 \mathrm{~nm}$ mmu-miR-200c precursor + E2F3 3'UTR: $0.705 \pm 0.061 ; n=3 ;{ }^{* * *} p<0.005,{ }^{* *} p<$ 0.01 , independent-samples $t$ test). $\boldsymbol{E}$, Overexpression of miR-200c (using the $p c D N A 6.2-E m G F P-$ miR-200c vector) in COS-7 cells led to a downregulation of luciferase expression from the pGL3-Sox2-3'UTR sensor vector containing the wild-type (WT) Sox2 3'UTR, which was rescued after site-directed mutagenesis of the miR-200c seed sequence within the Sox2 3 'UTR (Mut.). Transfection of the sensor vector together with "empty" pCDNA6.2-EmGFP vector served as negative control, and this value was set as 1 . (Sox2 3'UTR WT + pcDNA6.2-miR-200c: 0.737 \pm 0.037 ; Sox23'UTR Mut. + pCDNA6.2-miR-200c: $1.12 \pm 0.1 ; n=3 ;{ }^{*} p<0.05$, independent-samples $t$ test). $\boldsymbol{F}$, Overexpression of miR-200c (using the $p c D N A 6.2-E m G F P-m i R-200 c$ vector) in COS-7 cells led to a downregulation of luciferase expression from the $p G L 3-E 2 F 3-3^{\prime}$ UTR sensor vector containing the wild-type (WT) E2F3 3'UTR, which was rescued after site-directed mutagenesis of the two miR-200 c seed sequences within the E2F3 3'UTR (S2M and S2/4M). Transfection of the sensor vector together with "empty" pCDNA6.2-EmGFP vector served as negative control, and this value was set as 1. (E2F3 3'UTRWT + pcDNA6.2-miR-200c:0.667 + 0.09; E2F3 3'UTRS2M + pcDNA6.2-miR-200c: 1.3 $\pm 0.2 ; E 2 F 33^{\prime}$ UTR S2/4M + pcDNA6.2-miR-200c: 2.29 $\pm 0.19 ; n=3 ;{ }^{*} p<0.05$, ${ }^{* * *} p<0.005$ in the independent-samples $t$ test.) RLU, Relative luciferase units.

strongly suggest that the miR-200 family is engaged in an unilateral negative feedback loop with Sox2 and E2F3 ensuring the proper regulation of Sox 2 and E2F3 mRNA and/or protein levels in vMH neural progenitor cells (Fig. 9C), thereby facilitating their cell-cycle exit and differentiation into postmitotic neurons.

\section{Discussion}

We show here that the depletion of Dicer1-processed mature miRNAs and in particular of $m i R-200$ in the MHR of the Dicer1 $c K O$ embryos leads to the progressive loss of this region because of a strong increase of apoptotic cell death in the dorsal MHR and the failure of vMH neural progenitors to exit the cell cycle and to generate the appropriate numbers of neuronal offspring. We propose that the $m i R-200$ family belongs to a novel class of miRNAs that are engaged in an unilateral negative feedback loop with their direct targets Sox 2 and E2F3 (Fig. 9D), thereby promoting the transition from a proliferating and pluripotent/multipotent to a postmitotic and differentiating neural cell in the murine CNS.

Dicer1-processed miRNAs are not required for the patterning of the murine MHR

Although the progressive loss of the MHR in the Dicer1 cKO embryos resulted in a morphological defect at birth that strongly resembled the phenotype of mouse mutants for some of the IsO genes (Wurst and Bally-Cuif, 2001; Zervas et al., 2005), the MHR was correctly patterned along its A/P and D/V axes in the Dicer1 $c K O$ embryos. We concluded that the morphological defects of the Dicer 1 cKO embryos are not attributable to a deregulation of
IsO gene expression in the absence of Dicer1-processed miRNAs, including $m i R-200$ and $m i R-124$, one of the most abundant miRNAs in the brain (Lagos-Quintana et al., 2002). Similar observations were made in another conditional Dicer1 mutant [Wnt1-Cre; Dicer $1^{\text {flox/flox }}$ mice (Huang et al., 2010)] and in other organs/tissues after Dicer1 deletion (Harfe et al., 2005; Choi et al., 2008; Kawase-Koga et al., 2010), thus corroborating the assumption that Dicer1-processed miRNAs do not play a major role in early patterning events during mouse embryogenesis.

\section{Dicer1-processed miRNAs are necessary for the proper} survival of neural cells in the murine MHR

The massive increase of apoptotic cell death in the Dicer1 cKO embryos from E11.5 onward most likely caused the progressive dorsal $\mathrm{MH}$ tissue loss in these embryos. Increased apoptosis is a unifying feature of almost all conditional Dicer 1 mutants, particularly in the nervous system (Coolen and Bally-Cuif, 2009). Proapoptotic proteins were relatively enriched, whereas pro-survival proteins were depleted in Dicer1-deficient neural stem cells (NSCs) (Kawase-Koga et al., 2010), and it is therefore very likely that proapoptotic and/or prosurvival pathways are also deregulated in the MHR of our Dicer 1 cKO mice. However, the far lesser amount of apoptotic cell death in the mutant ventral MHR, especially at midgestational stages, cannot explain the drastic reduction of mDA, RN, and 5-HT but not of OM neurons observed already at these early stages after depletion of Dicer1-processed mature miRNAs in the Dicer1 cKO embryos. 
A

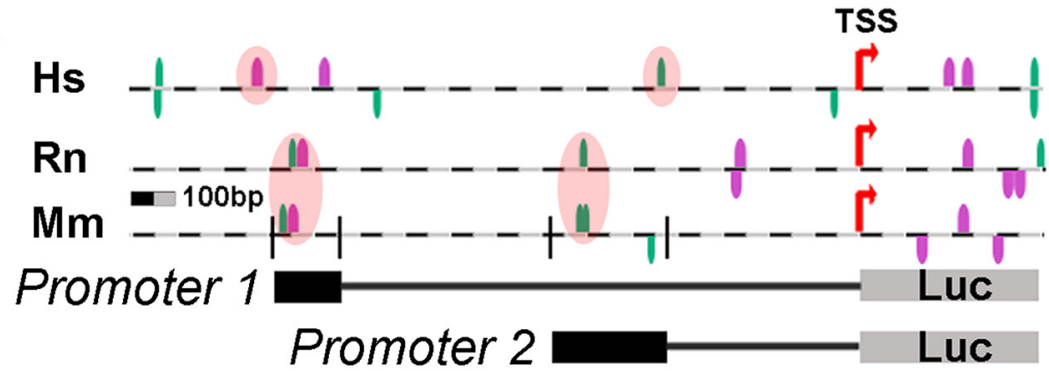

B

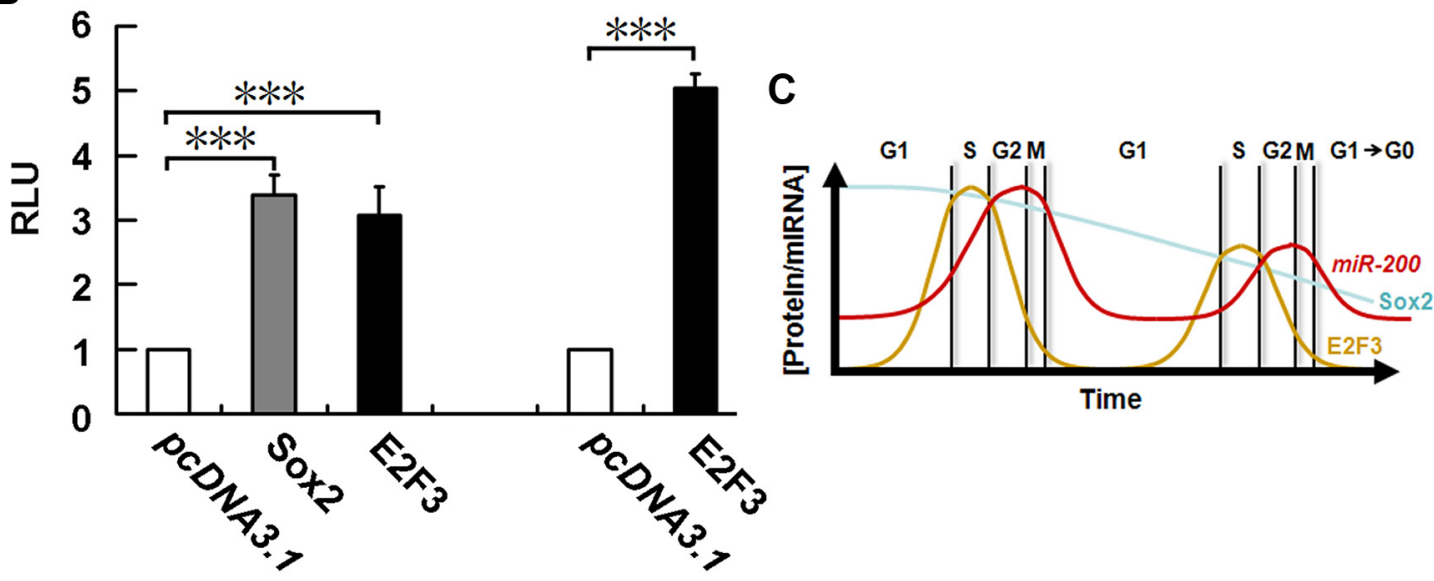

\section{Promoter $1 \quad \overline{\text { Promoter } 2}$}

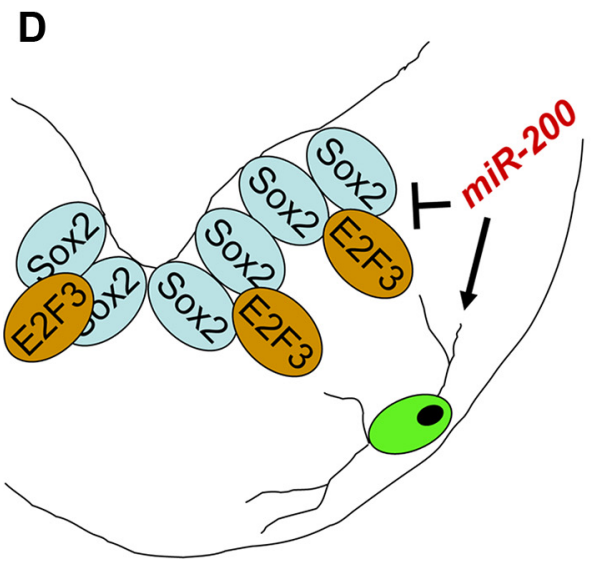

Neural progenitor cell

Neuron

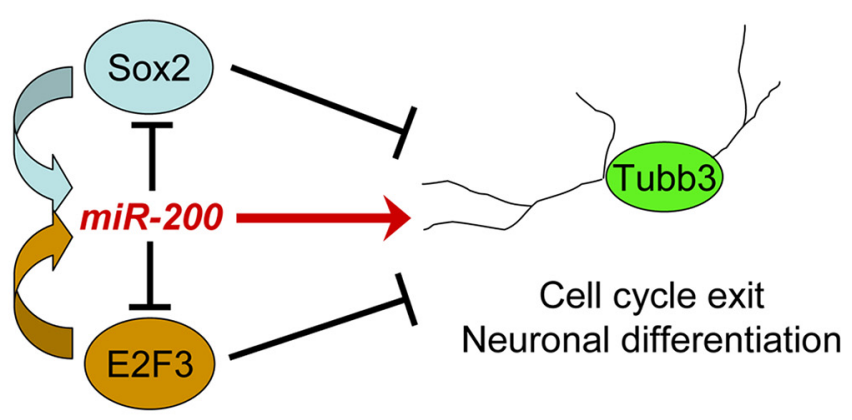

Figure 9. The mmu-miR-200c/141 promoter is activated by Sox2 and E2F3. A, Position and sequence of conserved (highlighted by pink ovals) BSs for Sox2 (magenta) and E2F (green) TFs within the human $(\mathrm{Hs})$, rat (Rn), and mouse (Mm) miR-200c/141 distal (Promoter 1) and proximal (Promoter 2) promoter regions. The mouse mmu-miR-200c/141 promoter regions (black boxes) were cloned in front of the Luciferase (Luc) CDS to obtain the corresponding reporter vectors. TSS, Transcription start site. B, Strong activation of the distal (Promoter 1) mmu-miR-200c/141 promoter region was seen after cotransfection of the reporter vector and Sox2 or E2F3 CDNA in HEK-293 cells. An even stronger activation of the proximal (Promoter 2) mmu-miR-200c/141 promoter region was detected after cotransfection of the reporter vector and E2F3 CDNA. Cotransfection of the reporter vectors and pCDNA3.1 ("empty") vector was used as negative control, and this value was set as 1. [pGL3-mmu-miR-200c/141 (Promoter 1) + Sox2:3.38 \pm 0.31;pGL3-mmu-miR-200c/141 (Promoter 1) + E2F3:3.08 \pm 0.44;pGL3-mmu-miR-200c/141 (Promoter 2) + E2F3:5.03 \pm 0.23; $n=4 ;{ }^{* * *} p<0.001$, independent-samples $t$ test). RLU, Relative luciferase units. C, The cyclic expression of E2F3 protein and presumably stronger regulatory interaction between E2F3 and miR-200 (more E2F3/miR-200 BSs within the miR-200/141 promoter/E2F3 3'UTR, respectively, compared with Sox2) are predicted to result in an oscillatory expression of E2F3/miR-200 and gradual reduction of Sox2 (blue)/E2F3 (brown) protein and miR-200 (red) miRNA levels in neural stem/progenitor cells, thereby promoting their cell-cycle exit and neuronal differentiation. Note that we do not provide any evidence for an oscillatory expression of miR-200 family members in neural stem/progenitor cells. G1, S, G2, M, GO, Phases of the cell cycle. D, Proposed model for the unilateral negative feedback loop between Sox2/E2F3-mediated activation of miR-200 (red) transcription and, in turn, miR-200-mediated translational inhibition of Sox2 (blue circles)/E2F3 (brown circles) expression in neural stem/progenitor cells located within the VZ/SVZ and IZ of the murine MHR. Note that these two TFs and miR-200c are coexpressed in neural stem/progenitor cells. The unilateral negative feedback loop between miR-200 and Sox2/E2F3 promotes the cell-cycle exit and neuronal differentiation of vMH neural progenitors.

$M i R-200$ family miRNAs promote the cell-cycle exit and neuronal differentiation of vMH neural progenitors

Another reason for the strong reduction of selected vMH neuronal populations in the Dicer $1 \mathrm{cKO}$ embryos was the failure of the corresponding neural progenitors to exit the cell cycle and to generate the appropriate amount of postmitotic neurons. This finding might also explain the relative sparing of the OM neurons in the mutant embryos: OM neurons are among the earliest-born neurons in the murine ventral midbrain [approximately E9.5 (Prakash et al., 2009)] and might thus have become postmitotic by their majority before the depletion of Dicer1-processed miRNAs in the Dicer 1 cKO embryos affected their progenitors. In support of 
our findings, Dicer1-deficient cortical NSCs also fail to generate the appropriate amount of neuronal and glial progeny and undergo premature apoptosis in the absence of growth-promoting factors, although obvious cell-cycle defects were not detected in these cases (De Pietri Tonelli et al., 2008; Andersson et al., 2010; Kawase-Koga et al., 2010).

miRNAs are widely implicated in the cell-cycle control of pluripotent/multipotent stem/progenitor cells and in their differentiation into a committed cell fate (Wang and Blelloch, 2009; Ivey and Srivastava, 2010; Mallanna and Rizzino, 2010). However, miRNAs can persist in neural stem/progenitor cells at relatively high levels and over a considerable time after Dicer 1 inactivation (Andersson et al., 2010). In search for the most strongly depleted miRNA(s) in the MHR of the Dicer1 cKO embryos, we identified the entire $m i R-200$ family as possible candidates that might cause the cell-cycle exit/differentiation defects in the mutants. miR$200 c$, a member of this family, is highly expressed in neural stem/ progenitor cells of the MHR and other regions of the brain (data not shown), suggesting a function of this miRNA family in multipotent neural stem/progenitor cells. In fact, overexpression of miR-200 family members promoted, whereas the knockdown of this family in primary vMH cultures or their loss in the Dicer 1 cKO embryos inhibited, the cell-cycle exit and neuronal differentiation of proliferating vMH neural progenitors. It appears that this function of the miR-200 family is highly context dependent: in some cases, these miRNAs promote (Brabletz and Brabletz, 2010), whereas in other cases they rather inhibit, the differentiation of pluripotent or dedifferentiated stem cells (Lin et al., 2009; Gill et al., 2011).

\section{$m i R-200$ and their targets Sox 2 and $\mathrm{E} 2 \mathrm{~F} 3$ are engaged in a unilateral negative feedback loop to direct cell-cycle exit and differentiation of neural progenitors}

We found that the $m i R-200$ family (in particular $m i R-200 c$ ) promotes cell-cycle exit and neuronal differentiation of vMH neural progenitors by downregulating Sox 2 and E2F3 expression in these cells and that miR-200c directly targets the Sox 2 and E2F3 mRNAs via specific BSs in their $3^{\prime}$ UTRs. Sox2 is required in a dose-dependent manner for maintaining the multipotency of neural stem/progenitor cells and inhibiting their cell-cycle exit and differentiation into neurons or glial cells (Avilion et al., 2003; Graham et al., 2003; Pevny and Nicolis, 2010). E2F3 protein levels/activity accumulate cyclically during the late $\mathrm{G}_{1}$-phase of the cell cycle, thereby promoting the transition from $\mathrm{G}_{1}$ to $S$-phase in proliferating cells by activating genes involved in DNA replication and cell-cycle regulation (Leone et al., 1998; Humbert et al., 2000; Chong et al., 2009). Several of the E2F3-regulated genes also belong to proapoptotic/antiapoptotic, intracellular signaling, and other pathways implicated in cell survival and differentiation (Müller et al., 2001; DeGregori, 2002). Because the complete loss of activating E2F TFs (E2F1-E2F3) in vivo does not affect the proliferation of multipotent stem/progenitor cells but decreases their survival (Chong et al., 2009), miR-200 might additionally promote the survival of vMH neural progenitors by regulating E2F3 protein levels in these cells.

We also found that Sox 2 and E2F3 directly activate the distal and proximal promoter regions of the murine $m i R-200 c / 141$ gene cluster, in agreement with the coexpression of these two TFs and $m i R-200 c$ in neural progenitors. This unilateral negative feedback loop of Sox2/E2F3 and $m i R-200 c / 141$ is predicted to result in an oscillatory expression of E2 $3 / \mathrm{miR}-200$ in neural progenitors (Krol et al., 2010): initially high levels of Sox 2 and increasing levels of E2F3 protein activate $m i R-200 c / 141$ expression, which in turn lower Sox $2 / \mathrm{E} 2 \mathrm{~F} 3$ protein levels in these cells, leading to the downregulation of $m i R-200 c / 141$ and the (re-)activation of Sox $2 /$ E2F3 expression (Fig. 9C). This oscillatory regulation might thus contribute to the cyclic accumulation of E2F3 protein/transcriptional activity only during the late $\mathrm{G}_{1}$-phase of the cell cycle, despite the continuous expression of E2F3 mRNA in proliferating cells (Leone et al., 1998). In fact, E2F3 protein was accumulating aberrantly in Dicer 1-mutant S-phase neural progenitors. In addition, the miR-200-mediated negative regulation of the autoactivating Sox2 and E2F3 TFs (Adams et al., 2000; Tomioka et al., 2002) might result in a gradual reduction of Sox 2 and E2F3 protein levels and eventually lead to the complete silencing [below a certain threshold (Mukherji et al., 2011)] of these two and other pluripotency/multipotency and cell-cycle regulatory genes in neural progenitors (Fig. 9C). Our findings are also supported by data showing that the pluripotency factor Lin 28 binds to the pre-miR-200c stem loop and targets it for degradation, thereby inhibiting its processing into mature $m i R-200 c$ in undifferentiated cells (Heo et al., 2009). The miR-200 family might thus only become active when the neural progenitor cells transit to a more committed cell fate by downregulating the expression of pluripotency factors such as Lin28.

Altogether, our results strongly support the notion that the miR-200 family members cooperate to suppress the levels of Sox 2 and $\mathrm{E} 2 \mathrm{~F} 3$ proteins below a critical level, thereby enabling the cell-cycle exit of neural progenitors and subsequently their differentiation into neurons (Fig. 9D), although we cannot exclude that the two miR-200 seed sequence subgroups might slightly differ in their target genes (Uhlmann et al., 2010) and that the two miR-200 gene clusters might be regulated by a distinct set of transcriptional activators/repressors. We have studied the mutual regulation of Sox2/E2F3 and miR-200 using in vitro paradigms that might not reflect entirely the in vivo situation. The relatively subtle effects observed after miR-200 overexpression/ knockdown in cultured vMH cells indicate that, because of the early and widespread functions of the miR-200 family (Peter, 2009; Brabletz and Brabletz, 2010) as well as the early and redundant functions of the SoxB1 (including Sox2) (Pevny and Nicolis, 2010) and E2F (DeGregori, 2002) TFs during murine development, the generation of conditional mouse mutants for the two $m i R-200$ gene clusters comprising all five $m i R-200$ family members and for the SoxB1/E2F TFs expressed in neural stem/progenitor cells will be required to ultimately establish the function of the regulatory interaction of $m i R-200$ and Sox $2 / \mathrm{E} 2 \mathrm{~F} 3$ in these cells in vivo. Nevertheless, this miRNA family might represent an intermediate (third) functional group of miRNAs in the mammalian CNS, allocated between the ESCC miRNAs ensuring the pluripotent state of NSCs and neuron-specific miRNAs supporting the proper differentiation of these cells into neurons (Coolen and Bally-Cuif, 2009; Mallanna and Rizzino, 2010).

\section{References}

Adams MR, Sears R, Nuckolls F, Leone G, Nevins JR (2000) Complex transcriptional regulatory mechanisms control expression of the E2F3 locus. Mol Cell Biol 20:3633-3639. CrossRef Medline

Ameres SL, Horwich MD, Hung JH, Xu J, Ghildiyal M, Weng Z, Zamore PD (2010) Target RNA-directed trimming and tailing of small silencing RNAs. Science 328:1534-1539. CrossRef Medline

Andersson T, Rahman S, Sansom SN, Alsiö JM, Kaneda M, Smith J, O'Carroll D, Tarakhovsky A, Livesey FJ (2010) Reversible block of mouse neural stem cell differentiation in the absence of dicer and microRNAs. PLoS One 5:e13453. CrossRef Medline

Avilion AA, Nicolis SK, Pevny LH, Perez L, Vivian N, Lovell-Badge R (2003) Multipotent cell lineages in early mouse development depend on SOX2 function. Genes Dev 17:126-140. CrossRef Medline 
Bibel M, Richter J, Lacroix E, Barde YA (2007) Generation of a defined and uniform population of CNS progenitors and neurons from mouse embryonic stem cells. Nat Protoc 2:1034-1043. CrossRef Medline

Brabletz S, Brabletz T (2010) The ZEB/miR-200 feedback loop-a motor of cellular plasticity in development and cancer? EMBO Rep 11:670-677. CrossRef Medline

Chi CL, Martinez S, Wurst W, Martin GR (2003) The isthmic organizer signal FGF8 is required for cell survival in the prospective midbrain and cerebellum. Development 130:2633-2644. CrossRef Medline

Choi PS, Zakhary L, Choi WY, Caron S, Alvarez-Saavedra E, Miska EA, McManus M, Harfe B, Giraldez AJ, Horvitz HR, Schier AF, Dulac C (2008) Members of the miRNA-200 family regulate olfactory neurogenesis. Neuron 57:41-55. CrossRef Medline

Chong JL, Wenzel PL, Sáenz-Robles MT, Nair V, Ferrey A, Hagan JP, Gomez YM, Sharma N, Chen HZ, Ouseph M, Wang SH, Trikha P, Culp B, Mezache L, Winton DJ, Sansom OJ, Chen D, Bremner R, Cantalupo PG, Robinson ML, Pipas JM, Leone G (2009) E2f1-3 switch from activators in progenitor cells to repressors in differentiating cells. Nature 462:930-934. CrossRef Medline

Cobb BS, Nesterova TB, Thompson E, Hertweck A, O’Connor E, Godwin J, Wilson CB, Brockdorff N, Fisher AG, Smale ST, Merkenschlager M (2005) T cell lineage choice and differentiation in the absence of the RNase III enzyme Dicer. J Exp Med 201:1367-1373. CrossRef Medline

Coolen M, Bally-Cuif L (2009) MicroRNAs in brain development and physiology. Curr Opin Neurobiol 19:461-470. CrossRef Medline

De Pietri Tonelli D, Pulvers JN, Haffner C, Murchison EP, Hannon GJ, Huttner WB (2008) miRNAs are essential for survival and differentiation of newborn neurons but not for expansion of neural progenitors during early neurogenesis in the mouse embryonic neocortex. Development 135:3911-3921. CrossRef Medline

DeGregori J (2002) The genetics of the E2F family of transcription factors: shared functions and unique roles. Biochim Biophys Acta 1602:131-150. Medline

Ebert MS, Neilson JR, Sharp PA (2007) MicroRNA sponges: competitive inhibitors of small RNAs in mammalian cells. Nat Methods 4:721-726. CrossRef Medline

Fischer T, Guimera J, Wurst W, Prakash N (2007) Distinct but redundant expression of the Frizzled Wnt receptor genes at signaling centers of the developing mouse brain. Neuroscience 147:693-711. CrossRef Medline

Fischer T, Faus-Kessler T, Welzl G, Simeone A, Wurst W, Prakash N (2011) Fgf15-mediated control of neurogenic and proneural gene expression regulates dorsal midbrain neurogenesis. Dev Biol 350:496-510. CrossRef Medline

Gill JG, Langer EM, Lindsley RC, Cai M, Murphy TL, Kyba M, Murphy KM (2011) Snail and the microRNA-200 family act in opposition to regulate epithelial-to-mesenchymal transition and germ layer fate restriction in differentiating ESCs. Stem Cells 29:764-776. CrossRef Medline

Graham V, Khudyakov J, Ellis P, Pevny L (2003) SOX2 functions to maintain neural progenitor identity. Neuron 39:749-765. CrossRef Medline

Guillemot F, Zimmer C (2011) From cradle to grave: the multiple roles of fibroblast growth factors in neural development. Neuron 71:574-588. CrossRef Medline

Guo C, Qiu HY, Huang Y, Chen H, Yang RQ, Chen SD, Johnson RL, Chen ZF, Ding YQ (2007) Lmxlb is essential for Fgf8 and Wntl expression in the isthmic organizer during tectum and cerebellum development in mice. Development 134:317-325. CrossRef Medline

Harfe BD, McManus MT, Mansfield JH, Hornstein E, Tabin CJ (2005) The RNaseIII enzyme Dicer is required for morphogenesis but not patterning of the vertebrate limb. Proc Natl Acad Sci U S A 102:10898-10903. CrossRef Medline

Heo I, Joo C, Kim YK, Ha M, Yoon MJ, Cho J, Yeom KH, Han J, Kim VN (2009) TUT4 in concert with Lin28 suppresses microRNA biogenesis through pre-microRNA uridylation. Cell 138:696-708. CrossRef Medline

Hirata H, Tomita K, Bessho Y, Kageyama R (2001) Hes1 and Hes3 regulate maintenance of the isthmic organizer and development of the $\mathrm{mid} / \mathrm{hind}-$ brain. EMBO J 20:4454-4466. CrossRef Medline

Huang T, Liu Y, Huang M, Zhao X, Cheng L (2010) Wnt1-cre-mediated conditional loss of Dicer results in malformation of the midbrain and cerebellum and failure of neural crest and dopaminergic differentiation in mice. J Mol Cell Biol 2:152-163. CrossRef Medline

Humbert PO, Verona R, Trimarchi JM, Rogers C, Dandapani S, Lees JA
(2000) E2f3 is critical for normal cellular proliferation. Genes Dev 14:690-703. Medline

Huntzinger E, Izaurralde E (2011) Gene silencing by microRNAs: contributions of translational repression and mRNA decay. Nat Rev Genet 12:99-110. CrossRef Medline

Ivey KN, Srivastava D (2010) MicroRNAs as regulators of differentiation and cell fate decisions. Cell Stem Cell 7:36-41. CrossRef Medline

Kawase-Koga Y, Low R, Otaegi G, Pollock A, Deng H, Eisenhaber F, MaurerStroh S, Sun T (2010) RNAase-III enzyme Dicer maintains signaling pathways for differentiation and survival in mouse cortical neural stem cells. J Cell Sci 123:586-594. CrossRef Medline

Kimmel RA, Turnbull DH, Blanquet V, Wurst W, Loomis CA, Joyner AL (2000) Two lineage boundaries coordinate vertebrate apical ectodermal ridge formation. Genes Dev 14:1377-1389. Medline

Kozomara A, Griffiths-Jones S (2011) miRBase: integrating microRNA annotation and deep-sequencing data. Nucleic Acids Res 39:D152-D157. CrossRef Medline

Krichevsky AM, Sonntag KC, Isacson O, Kosik KS (2006) Specific microRNAs modulate embryonic stem cell-derived neurogenesis. Stem Cells 24:857-864. CrossRef Medline

Krol J, Loedige I, Filipowicz W (2010) The widespread regulation of microRNA biogenesis, function and decay. Nat Rev Genet 11:597-610. CrossRef Medline

Lagos-Quintana M, Rauhut R, Yalcin A, Meyer J, Lendeckel W, Tuschl T (2002) Identification of tissue-specific microRNAs from mouse. Curr Biol 12:735-739. CrossRef Medline

Lau P, Verrier JD, Nielsen JA, Johnson KR, Notterpek L, Hudson LD (2008) Identification of dynamically regulated microRNA and mRNA networks in developing oligodendrocytes. J Neurosci 28:11720-11730. CrossRef Medline

Leone G, DeGregori J, Yan Z, Jakoi L, Ishida S, Williams RS, Nevins JR (1998) E2F3 activity is regulated during the cell cycle and is required for the induction of S phase. Genes Dev 12:2120-2130. CrossRef Medline

Li R, Li Y, Kristiansen K, Wang J (2008) SOAP: short oligonucleotide alignment program. Bioinformatics 24:713-714. CrossRef Medline

Lin CH, Jackson AL, Guo J, Linsley PS, Eisenman RN (2009) Myc-regulated microRNAs attenuate embryonic stem cell differentiation. EMBO J 28:3157-3170. CrossRef Medline

Livak KJ, Schmittgen TD (2001) Analysis of relative gene expression data using real-time quantitative PCR and the 2(-Delta Delta $\mathrm{C}(\mathrm{T})$ ) method. Methods 25:402-408. CrossRef Medline

Mallanna SK, Rizzino A (2010) Emerging roles of microRNAs in the control of embryonic stem cells and the generation of induced pluripotent stem cells. Dev Biol 344:16-25. CrossRef Medline

Martinez NJ, Gregory RI (2010) MicroRNA gene regulatory pathways in the establishment and maintenance of ESC identity. Cell Stem Cell 7:31-35. CrossRef Medline

McMahon AP, Bradley A (1990) The Wnt-1 (int-1) proto-oncogene is required for development of a large region of the mouse brain. Cell 62:1073-1085. CrossRef Medline

Mukherji S, Ebert MS, Zheng GX, Tsang JS, Sharp PA, van Oudenaarden A (2011) MicroRNAs can generate thresholds in target gene expression. Nat Genet 43:854-859. CrossRef Medline

Müller H, Bracken AP, Vernell R, Moroni MC, Christians F, Grassilli E, Prosperini E, Vigo E, Oliner JD, Helin K (2001) E2Fs regulate the expression of genes involved in differentiation, development, proliferation, and apoptosis. Genes Dev 15:267-285. CrossRef Medline

Nakamura T, Colbert MC, Robbins J (2006) Neural crest cells retain multipotential characteristics in the developing valves and label the cardiac conduction system. Circ Res 98:1547-1554. CrossRef Medline

Pauli A, Rinn JL, Schier AF (2011) Non-coding RNAs as regulators of embryogenesis. Nat Rev Genet 12:136-149. CrossRef Medline

Peng C, Fan S, Li X, Fan X, Ming M, Sun Z, Le W (2007) Overexpression of Pitx3 upregulates expression of BDNF and GDNF in SH-SY5Y cells and primary ventral mesencephalic cultures. FEBS Lett 581:1357-1361. CrossRef Medline

Peng C, Aron L, Klein R, Li M, Wurst W, Prakash N, Le W (2011) Pitx3 is a critical mediator of GDNF-induced BDNF expression in nigrostriatal dopaminergic neurons. J Neurosci 31:12802-12815. CrossRef Medline

Peter ME (2009) Let-7 and miR-200 microRNAs: guardians against pluripotency and cancer progression. Cell Cycle 8:843-852. CrossRef Medline Pettitt SJ, Liang Q, Rairdan XY, Moran JL, Prosser HM, Beier DR, Lloyd KC, 
Bradley A, Skarnes WC (2009) Agouti C57BL/6N embryonic stem cells for mouse genetic resources. Nat Methods 6:493-495. CrossRef Medline

Pevny LH, Nicolis SK (2010) Sox2 roles in neural stem cells. Int J Biochem Cell Biol 42:421-424. CrossRef Medline

Prakash N, Puelles E, Freude K, Trümbach D, Omodei D, Di Salvio M, Sussel L, Ericson J, Sander M, Simeone A, Wurst W (2009) Nkx6-1 controls the identity and fate of red nucleus and oculomotor neurons in the mouse midbrain. Development 136:2545-2555. CrossRef Medline

Puelles E, Annino A, Tuorto F, Usiello A, Acampora D, Czerny T, Brodski C, Ang SL, Wurst W, Simeone A (2004) Otx2 regulates the extent, identity and fate of neuronal progenitor domains in the ventral midbrain. Development 131:2037-2048. CrossRef Medline

Rubinson DA, Dillon CP, Kwiatkowski AV, Sievers C, Yang L, Kopinja J, Rooney DL, Zhang M, Ihrig MM, McManus MT, Gertler FB, Scott ML, Van Parijs L (2003) A lentivirus-based system to functionally silence genes in primary mammalian cells, stem cells and transgenic mice by RNA interference. Nat Genet 33:401-406. CrossRef Medline

Schwarz M, Alvarez-Bolado G, Urbánek P, Busslinger M, Gruss P (1997) Conserved biological function between Pax-2 and Pax-5 in midbrain and cerebellum development: evidence from targeted mutations. Proc Natl Acad Sci U S A 94:14518-14523. CrossRef Medline

Silahtaroglu AN, Nolting D, Dyrskjøt L, Berezikov E, Møller M, Tommerup N, Kauppinen S (2007) Detection of microRNAs in frozen tissue sections by fluorescence in situ hybridization using locked nucleic acid probes and tyramide signal amplification. Nat Protoc 2:2520-2528. CrossRef Medline

Simon HH, Saueressig H, Wurst W, Goulding MD, O'Leary DD (2001) Fate of midbrain dopaminergic neurons controlled by the engrailed genes. J Neurosci 21:3126-3134. Medline
Tomioka M, Nishimoto M, Miyagi S, Katayanagi T, Fukui N, Niwa H, Muramatsu M, Okuda A (2002) Identification of Sox-2 regulatory region which is under the control of Oct-3/4-Sox-2 complex. Nucleic Acids Res 30:3202-3213. CrossRef Medline

Uhlmann S, Zhang JD, Schwäger A, Mannsperger H, Riazalhosseini Y, Burmester S, Ward A, Korf U, Wiemann S, Sahin O (2010) miR-200bc/429 cluster targets PLCgammal and differentially regulates proliferation and EGF-driven invasion than miR-200a/141 in breast cancer. Oncogene 29:4297-4306. CrossRef Medline

Wang Y, Blelloch R (2009) Cell cycle regulation by MicroRNAs in embryonic stem cells. Cancer Res 69:4093-4096. CrossRef Medline

Wang Y, Baskerville S, Shenoy A, Babiarz JE, Baehner L, Blelloch R (2008) Embryonic stem cell-specific microRNAs regulate the G1-S transition and promote rapid proliferation. Nat Genet 40:1478-1483. CrossRef Medline

Wittmann DM, Blöchl F, Trümbach D, Wurst W, Prakash N, Theis FJ (2009) Spatial analysis of expression patterns predicts genetic interactions at the mid-hindbrain boundary. PLoS Comput Biol 5:e1000569. CrossRef Medline

Wurst W, Bally-Cuif L (2001) Neural plate patterning: upstream and downstream of the isthmic organizer. Nat Rev Neurosci 2:99-108. CrossRef Medline

Wurst W, Auerbach AB, Joyner AL (1994) Multiple developmental defects in Engrailed-1 mutant mice: an early mid-hindbrain deletion and patterning defects in forelimbs and sternum. Development 120:2065-2075. Medline

Zervas M, Blaess S, Joyner AL (2005) Classical embryological studies and modern genetic analysis of midbrain and cerebellum development. Curr Top Dev Biol 69:101-138. CrossRef Medline 